\title{
Teaching-learning-based optimization algorithm for solving structural damage detection problem in frames via changes in vibration responses
}

\author{
Rahul Dev Kundu ${ }^{1}$ Mayank Mishra ${ }^{2}$ (D) Damodar Maity ${ }^{1}$
}

Received: 10 April 2021 / Accepted: 20 September 2021

(C) The Author(s), under exclusive licence to Springer Nature Switzerland AG 2021

\begin{abstract}
Optimization algorithms are primarily responsible for efficiency in vibration-based damage detection particularly when utilizing the inverse approach. A complex problem of damage detection tends to converge into local minima, generated by a false damaged state which produces a response that is almost similar to the actual damaged state. Hence, there is a need for an efficient and accurate soft computing technique that can find the global minima or the actual damaged state. Recently, the teaching-learning based optimization (TLBO) algorithm has become quite popular due to its superior performance especially when compared to other metaheuristic algorithms. In this paper, damage estimation capability of the TLBO for frame structures and a benchmark problem of cantilever beam is studied and comparisons are made with some established soft computing techniques. TLBO is observed to produce better results relative to the other artificial intelligence-based techniques used for structural health monitoring.
\end{abstract}

Keywords Damage detection · Structural health monitoring · Soft Computing · Optimization algorithm · Artificial intelligence

\section{Introduction}

During the service time, components of a structure become damaged due to several external factors such as accidental or intentional overloading, fire, corrosion, repetitive loads, blast loads and natural disasters like earthquake. This damage, if not detected early enough, usually worsens with time and eventually results in failure of the whole structure. To prevent this type of unnoticed accidental failure, quick and proper assessment of the damage is crucial.

Mayank Mishra

mayank@iitbbs.ac.in

Rahul Dev Kundu

rahuldevkundu97@gmail.com

Damodar Maity

dmaity@ civil.iitkgp.ac.in

1 Department of Civil Engineering, Indian Institute of Technology, Kharagpur, 721302, India

2 School of Infrastructure, Indian Institute of Technology, Bhubaneswar, 752050, India
An assessment of damage should include identification, localization and quantification of the damage. If the damage is visible, its assessment can be carried out with relative ease. However, any damage embedded inside a structural component can only be assessed by non-destructive tests. Non-destructive tests can be of two types, i.e., local and global. Local methods utilize ultrasonic pulse velocity, thermal testing, acoustic emission tests, magnetic field and eddy current. These tests usually require previous knowledge of the vicinity of the damaged section and often they have to be repeated throughout the whole structure, which may be time-consuming and uneconomical. The damaged portion also has to be easily accessible for these methods to be effectively applied. Vibrationbased investigations to understand global behavior such as mode-shapes and frequencies on the contrary, are less time consuming, can be carried out without disturbing the structure [1] depending on case-to-case basis. Furthermore, they are also less costly in many instances as compared to modern laser scanning techniques [2] and in-depth inspections [3-5].

Incorporation of any damage structures can lead to deviation in their dynamic properties such as the natural 
frequencies, modal shapes and their curvatures, modal strain energy, modal stiffness and flexibility matrices as well as frequency response functions (FRF). In vibration-based methods, these deviations can be used as data to evaluate the damage in the structural elements. The approach for damage detection from the vibration response can be direct or inverse. In the direct approach, the changes on the structural dynamic properties are obtained by incorporating different damage conditions, whereas, in the inverse approach, the damage extents and locations are derived from the deviation in the dynamic properties.

In essence, an inverse approach is considered where a mathematical relationship is first constructed between damage condition and the corresponding structural response. Then, an objective function is formulated, which calculates the error in the responses of the actual damage scenario and the finite element formulated potential damage condition. Finally, a suitable optimization technique is used to minimize this objective function. The mathematical relationship between structural vibration response and the location as well as extent of damages is very complex, involving a large number of local optima [6-8]. Hence, conventional optimization algorithms often fail to assess the damage correctly. However, it is possible to overcome this difficulty by implementing guided random search techniques like genetic algorithm (GA) [9-13]. Most of these metaheuristic algorithms are nature-inspired stochastic search techniques and are computationally efficient, as they possess the ability to implement distributed computing.

However, these algorithms face two primary difficulties. Firstly, most of them require the proper assignment of suitable values for algorithm-specific parameters which would be unique to those algorithms for a certain detection study [14]. For example, GA requires the provision of optimum values of crossover probability and mutation probability [15], ant-colony optimiser requiring its pheromone evaporation rate related parameters [16, 17], while PSO requires to define proper constriction coefficients and inertia factor in order to obtain the best results [18]. This parameter-tuning needs additional scrutiny which increases the actual implementation time. Secondly, even some highly efficient variants of GA, PSO and ACO either fail to obtain the true damaged state or consume enormous time when problem dimension becomes large. For this reason, these algorithms become unsuitable for application in case of high-dimensional structures like multi-storey frames.

In this study, we hypothesize that one emerging optimization algorithm named teaching-learning-based optimization (TLBO) has the potential to be extremely effective and efficient in case of multi-storey frames. The first reason is TLBO does not consist of any algorithm-specific parameter, which implies there is no practical preparation time required for parameter tuning. Secondly, the population update schemes are very simple yet extremely effective and efficient in spite of double evaluation of the objective function. In various recent literature's also, this algorithm has shown promising results when applied on beam, truss and plate structures [2, 19-21]. However, there is a need to study the performance of this algorithm on frame structures exclusively, since frames consist of more number degrees of freedom compared to beam or trusses, resulting in the escalation of the optimization problem dimension. Here, the application of TLBO is explored on multi-storey frame structures to compare its damage estimation capability with efficient variants of some well-established algorithms in high-dimensional problem.

\section{Literature review}

Detection of structural damage using dynamic response can be traced back to the work of Yang et al. [22], where cracks were identified using changes in mass, stiffness and damping matrices. Afterwards, Doyle and James [23] used GA with the spectral element method for crack detection. Ceravolo et al. [24] used the neural network to detect structural fault from the dynamic response. Kosmatka and Ricles [25] used experimentally obtained modes and frequencies to detect damage in structures using weighted sensitivity analysis. Being least prone to measurement error, natural frequencies are used extensively as a unique dynamic response. The error of estimation in case of other dynamic responses like modal damping and mode shapes can be up to twenty times worse than that of natural frequency [6]. However, using only natural frequencies causes symmetry errors in damage estimates and they are not very sensitive to minute damage.

Pandey et al. [26] provided an extensive overview of damage detection methods based on vibration characterstics. They were the first to suggest the curvature of the mode shapes as a suitable index for damage estimation in beams. They also proposed that curvature could be obtained numerically by using modal displacement through central difference approximation. Wang and Deng [27] used the wavelet transform on displacement data for damage estimation. Sampaio et al. [28] used experimental data of a real bridge and demonstrated the FRF curvature method to assess the damage. Zou et al. [29] provided a comprehensive review of model-dependent vibration-based damage detection in composite structures and discussed methods based on modal analysis, frequency domain [30], time domain and impedance domain. Tripathy and Maity [31] used the curvature damage factor with back-propagation training algorithm to detect structural damage. Maity and Saha [32] observed that strain values can produce better damage estimates than displacements when used in a neural network. 
Krawczuk [33] combined GA with the gradient-based technique for detection of damage in the beam-like structures. Genetic algorithm was also used by Maity and Tripathy [34] to predict damage in structures to minimize deviations in natural frequencies. Moaveni et al. [35] performed modal identification using the eigensystem realization algorithm (ERA) and was able to detect damage in a composite beam. Fang and Perera [36] used power mode shapes instead of conventional mode shapes to identify damage in linear structures. Artificial immune pattern classifier (AIPR) was proposed for damage classification by Chen and Zhang [37] and validated using a benchmark structure.
Several hybrid soft computing algorithms like neurogenetic algorithm [38], hybrid real GA [39] and radial basis neural network [40] have been used for effective damage identification and localization. Principle component analysis and pattern recognition were used by Bandara et al. [41] for FRF based damage identification. Later, swarm-based intelligence techniques were used by various researchers to achieve better efficiency and consistency. Ant colony optimization (ACO) [42-44] was used to assess damage in truss and beam using natural frequencies. Another swarm inspired technique, the particle swarm optimization (PSO) was implemented on FRF response by

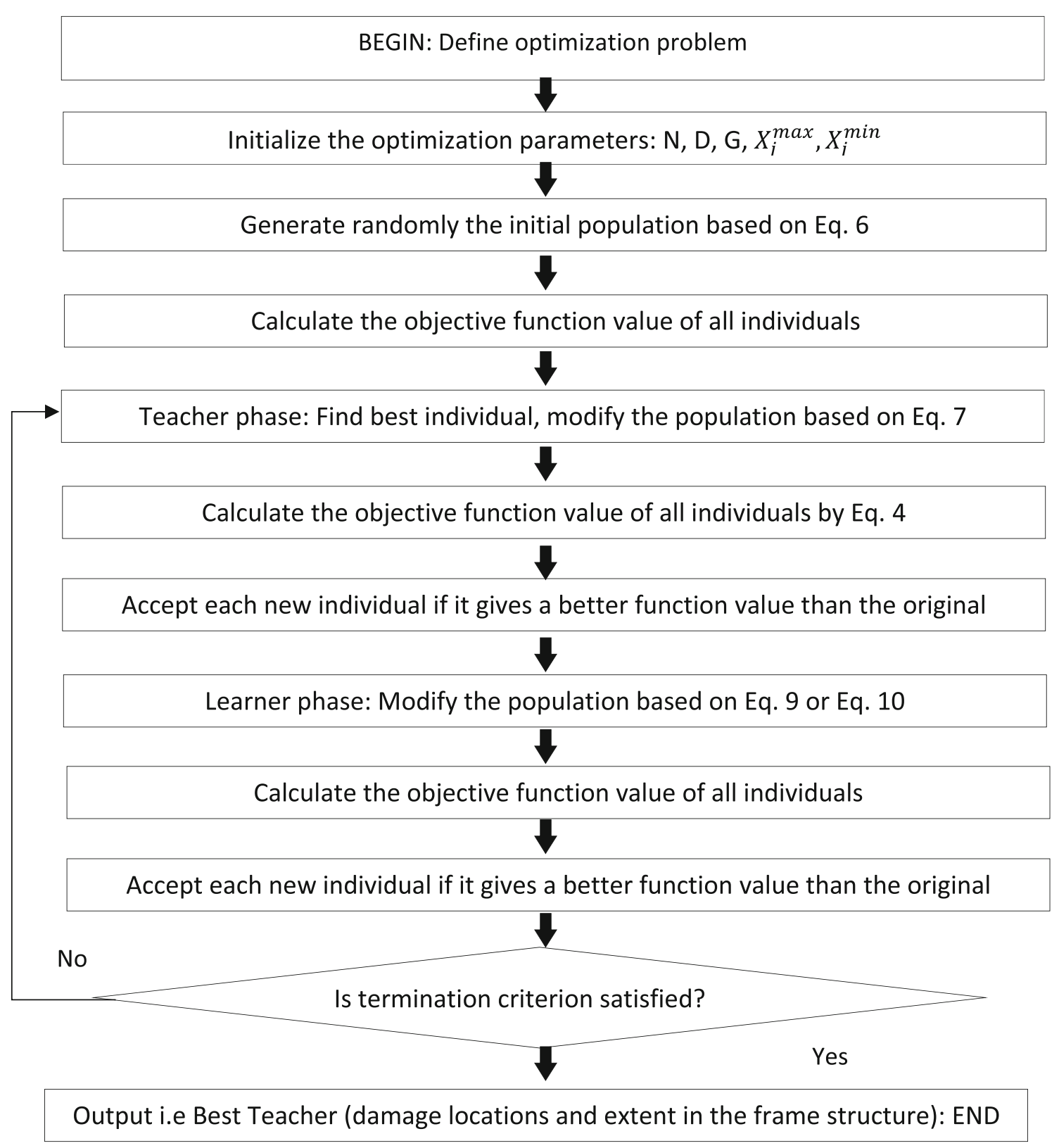

Fig. 1 Steps of TLBO employed for damage detection in frames 
Huang et al. [45] and Mohan et al. [46] for the assessment of structural damage. PSO was also combined with other algorithms and modified by many researchers [47-50]. Several variants of these algorithms were also investigated and it was discovered that they can improve the results. In this regard, unified particle swarm optimization (UPSO) was used to detect damage in composite structures [51] and laminated composite shells by Jebieshia et al. [52]. Ant lion optimization (ALO) was also used for damage detection by Mishra et al. [4]. Further, Hooke-Jeeves local search was combined with ACO by Shakya et al. [53] to provide improved damage detection results in structures. However, few researchers have applied these algorithms on frame structures, and most of them have reported the best estimate instead of a confidence interval (CI) estimate, thereby lacking any estimation consistency measure.

Besides the common algorithms, other inverse based techniques such as charged system search [54], adaptive real-parameter simulated annealing GA [55], artificial beecolony [56], moth-flame optimisation [57], bird mating optimizer [58] and cooperative co-evolutionary GA [59] are also used extensively in structural damage identification. Ding et al. [60] used modified Bare-bones Gaussian tree seeds algorithm for damage detection in beam and truss using time-domain data. Kim et al. [61] used differential evolution algorithm to assess multiple damage sites and their extents in truss structures. Aval and Mohebian [62] detected member and joint damage in plane truss and plane frame using improved biology migration algorithm. Ghahremani et al. [63] utilized covariance matrix adaptation-evolution strategy (CMA-ES) method to detect damages in a plane truss and a plane frame structure and compared its performance with GA and PSO. Recently, Barman et al. [64] compared the damage estimation capacity of several variants of swarm-based search algorithms for truss structures.

Teaching-learning-based optimization algorithm has been presented by Rao et al. [65] for optimization in the design problems of mechanical systems. Due to its simplicity and effectiveness, TLBO was studied in several other engineering problems [66-73]. Regarding structural damage detection, Pholdee and Bureerat [74] combined TLBO with Broyden-Fletcher-Goldfarb-Shanno algorithm (BFGS) to detect damage in complex truss structures using natural frequencies. They also compared the performance of various state-of-the-art meta-heuristics including the TLBO for modal data-based damage detection in trusses. Fallahian et al. [75] used TLBO to optimize acceleration responses for structural damage detection. Khatir et al. [76] used isogeometric analysis and applied a two-stage process for damage detection in beam structures with modal strain energy and TLBO. Mishra et al. [2] also compared the performance of the TLBO for damage detection with nine other meta-heuristic algorithms for large scale truss structures. However, the performance of TLBO for frame structures was not evaluated and their study was limited to truss structures only.

In this study, the application of TLBO in damage detection is extended to various frame structures. Both plane frame and space frame are taken into consideration. The damage estimation performance is compared with other optimization techniques in terms of convergence and the damage estimation accuracy. Damage scenarios with noisy environments are also considered along with the noise-free scenarios to simulate a real-life situation.

\section{Theoretical formulation}

\section{Obtaining dynamic response}

As the inverse approach utilizes the deviation in the dynamic behaviour of damaged and undamaged structure for damage prediction, the first step is to obtain these dynamic responses. In this study, natural frequencies and the respective mode shapes associated with them are considered as the dynamic responses since they can indicate any variation in material and geometric properties, i.e., damages. Usually, these structures are idealized as a multidegree of freedom (MDOF) system with $n$ number of degrees of freedom (DOFs). Using the finite element method, the equation of motion of this n-DOF system is obtained.

$[m]\{\ddot{u}\}+[k]\{u\}=\{f\}$

Where, $[m]$ and $[k]$ are $n \times n$ dimensional mass and stiffness matrices of the system, $\{u\}$ is the time-dependent

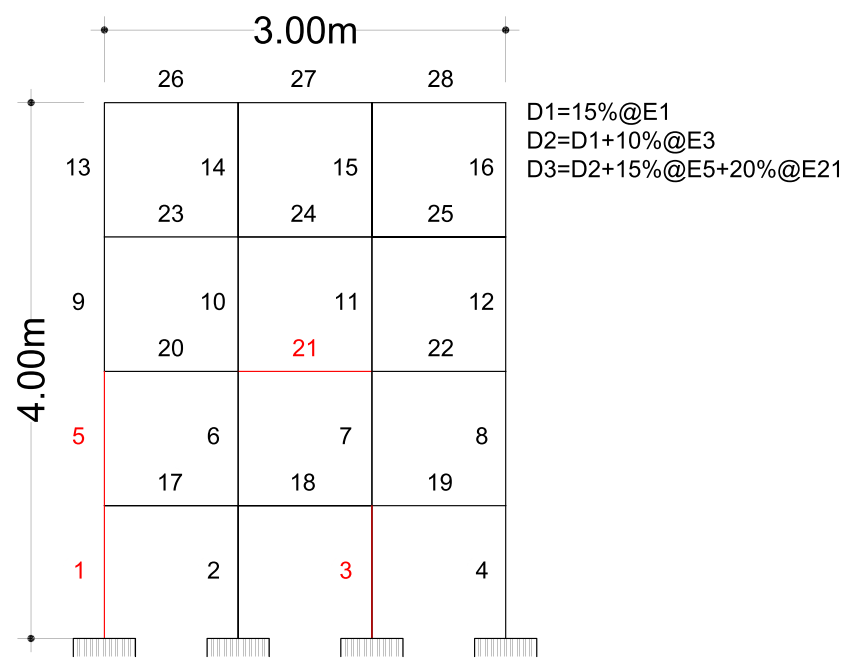

Fig. 2 Plane frame with damaged elements marked in red color 
displacement vector, and $\{f\}$ is the time-dependent vector denoting the external load applied on the system. Now as the natural frequencies do not depend on the applied force, one can choose $\{f\}=\{0\}$, and also if $\{u\}$ is assumed as exponential $A e^{i \omega t}\{\phi\}$ form, the equation of motion becomes

$\left(-\omega^{2}[m]+[k]\right)\{\phi\}=\{0\}$

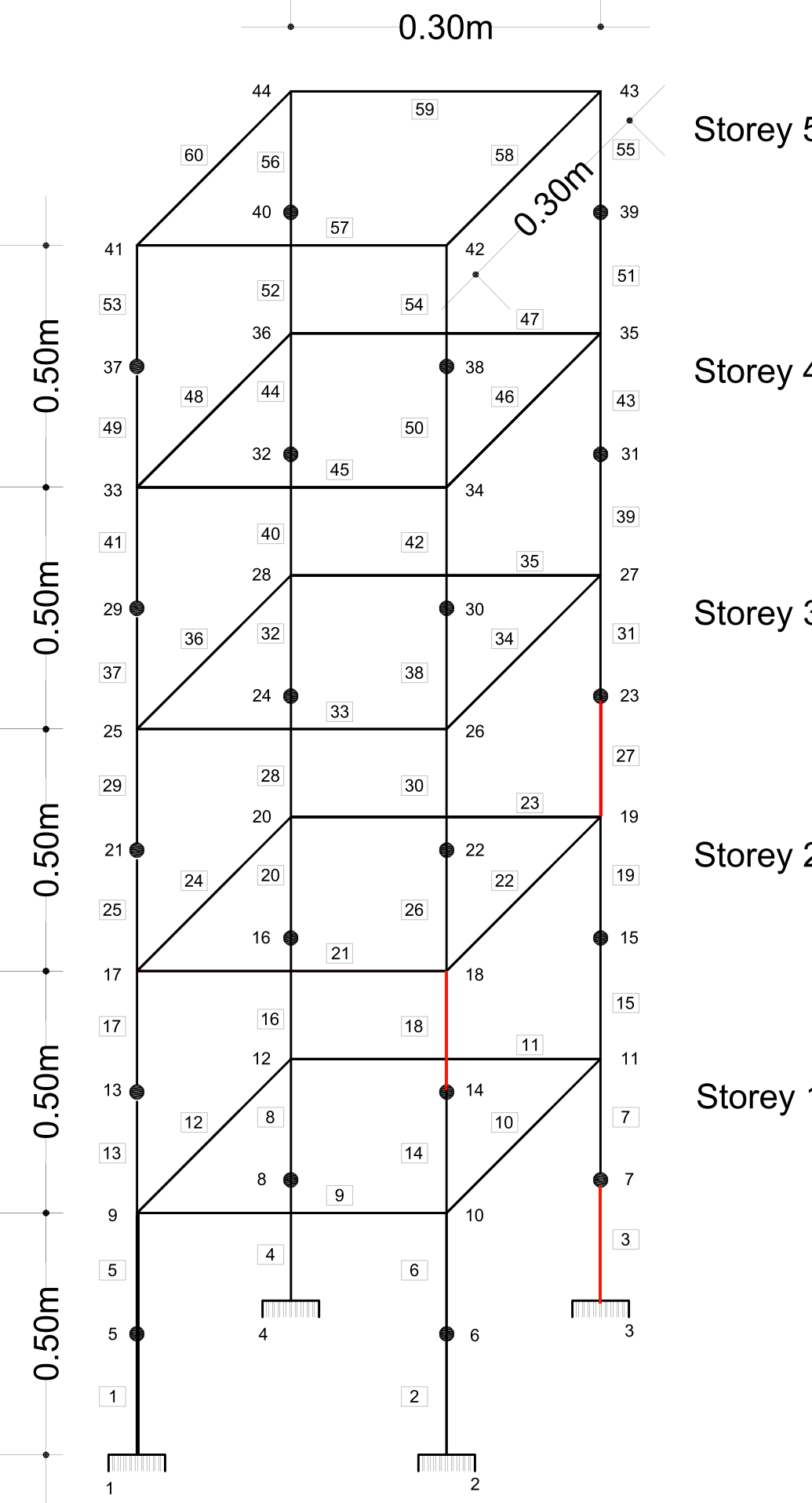

Fig. 3 Space frame with damaged elements marked in red color (numbers in square bracket indicating element number in FE model, filled black circle denotes the nodes considered inside a continuous column for better visibility and plain assigned numbers as node numbers for all) 
Table 1 Properties and damage cases of plane frame and space frame from Majumdar et al. [83]

\begin{tabular}{|c|c|c|c|c|c|c|}
\hline \multirow[t]{2}{*}{ Frame type } & \multirow{2}{*}{$\begin{array}{l}\text { Elastic modulus } \\
\left(\mathrm{N} / \mathrm{m}^{2}\right)\end{array}$} & \multirow{2}{*}{$\begin{array}{l}\text { Density } \\
\left(\mathrm{kg} / \mathrm{m}^{3}\right)\end{array}$} & \multirow{2}{*}{$\begin{array}{l}\text { Cross-section } \\
\left(\mathrm{m}^{2}\right)\end{array}$} & \multicolumn{3}{|c|}{ Damage state } \\
\hline & & & & D1 & D2 & D3 \\
\hline Plane frame & $200 \times 10^{9}$ & 7800 & $0.02 \times 0.02$ & $15 \% @ \mathrm{E}_{1}$ & $\begin{array}{l}15 \% @ \mathrm{E}_{1} \\
10 \% @ \mathrm{E}_{3}\end{array}$ & $\begin{array}{l}15 \% @ \mathrm{E}_{1} \\
10 \% @ \mathrm{E}_{3} \\
15 \% @ \mathrm{E}_{5} \\
20 \% @ \mathrm{E}_{21}\end{array}$ \\
\hline Space frame & $200 \times 10^{9}$ & 7800 & $0.025 \times 0.006$ & $20 \% @ \mathrm{E}_{3}$ & $\begin{array}{l}20 \% @ \mathrm{E}_{3} \\
15 \% @ \mathrm{E}_{27}\end{array}$ & $\begin{array}{l}20 \% @ \mathrm{E}_{3} \\
10 \% @ \mathrm{E}_{18} \\
15 \% @ \mathrm{E}_{27}\end{array}$ \\
\hline
\end{tabular}

Excluding the trivial solution $\{\phi\}=\{0\}$, this becomes an eigenvalue problem with n number of eigenvalues $\left(\omega^{2}\right)$ and respective $n$ eigenvectors $(\{\phi\})$ associated with them. Square roots of these eigenvalues represent the natural frequencies of the MDOF system and the eigenvectors represent the mode shapes corresponding to those frequencies.

\section{Damage model}

Generally, the occurrence of a less amount of damage which is not visible from outside has a significant effect on the stiffness but negligible effect on the mass distribution of a structural system. Hence, we assume that only the stiffness matrix in the Eq. 1 will change upon incorporating damage. Let $\alpha$ be the damage extent or the stiffness reduction factor (Perera and Ruiz [77]) with a range of 0 to 1 , which denotes two extreme cases i.e. undamaged and completely damaged respectively. Now, for a damaged element, the updated element stiffness matrix will be

$[k]_{e, \text { damaged }}=(1-\alpha)\left[k_{e}\right]$

For $\mathrm{N}$ number of elements, there will be $\mathrm{N}$ number of different $\alpha$ values. This whole set of $\mathrm{N}$ number of $\alpha$ values, i.e., $\left\{\alpha_{1}, \alpha_{2}, \ldots, \alpha_{N}\right\}$ is considered as a single damaged case.

\section{Objective function}

The objective function is formulated to minimize the deviation in the dynamic properties of the target structure with the actual damage and a simulated damaged condition. The dynamic properties considered here are the natural frequencies and mode shapes. Higher-order natural frequencies and

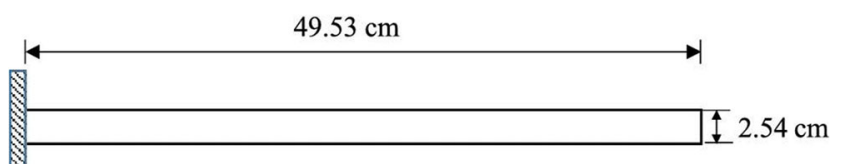

(a) Undamaged beam
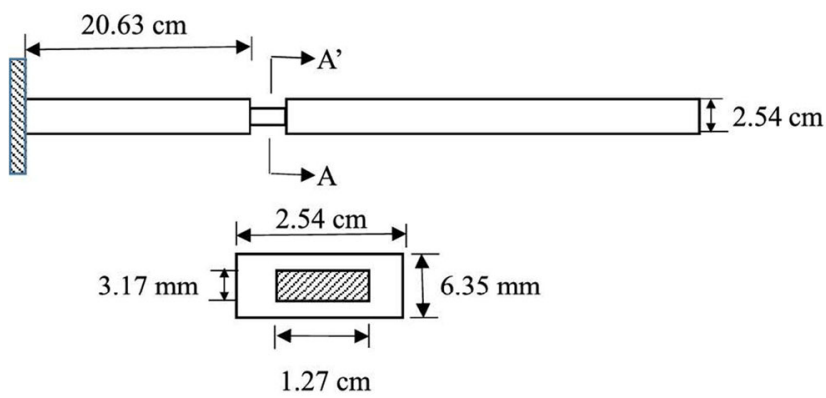

Section A-A'

(b) Damaged beam

Fig. 4 a) Aluminium cantilever beam taken from Yang et al. [22] b) damaged beam 
corresponding mode shapes are actually inconvenient to measure and are also prone to high magnitude of error. Therefore, only the first few are considered here. The objective function value (OFV) utilizes both the natural frequencies and the modal assurance criteria (MAC) as given below [39]:

$O F V=\sqrt{\frac{1}{n} \sum_{i=1}^{n}\left(\frac{f_{i}^{d}}{f_{i}^{a}}-1\right)^{2}}+\sum_{i=1}^{n}\left(1-M A C_{i i}\right)$

where

$M A C_{i i}=\frac{\left(\phi_{i}^{d^{T}} \phi_{i}^{a}\right)^{2}}{\left\|\phi_{i}^{d}\right\|^{2}\left\|\phi_{i}^{a}\right\|^{2}}$

Here, superscripts $d$ and $a$ denote the simulated damage case and actual damage case respectively. Superscript $T$ is the transpose operator. The number of modes considered is denoted by $n$. In this study, unless otherwise mentioned, $n=6$. Since the difference between the relative mode shape responses for three DOFs might be very large, they are scaled by dividing with the undamaged mode shape responses. This is advantageous, especially in noisy cases, as it ensures equal importance to all DOFs.

\section{Optimization algorithm for damage detection: TLBO}

Selection of an appropriate algorithm determines the efficiency and accuracy of any optimization-based damage detection problem. In this study, the teaching-learningbased optimization (TLBO) algorithm presented by Rao et al. [65] is employed which does not consist of any algorithm-specific parameter. This method mimics the betterment of students' performance in a classroom by teaching and learning and has been employed to solve diverse engineering problems [78, 79]. In the first stage of a single iteration, the teacher improves the students by teaching, and in the second phase, students learn from any other student in a classroom. A brief summary of the TLBO algorithm can be explained as follows:

\section{Initialization}

A population matrix $X$ with $P$ rows and $N$ columns is randomly initialized. Each row expresses one possible
Fig. 5 a) $\mathrm{OFV}$ vs function evaluation for ALO and TLBO,

b) Damage estimated with Lagrange multiplier method [87], GA [34], ALO [4] and TLBO

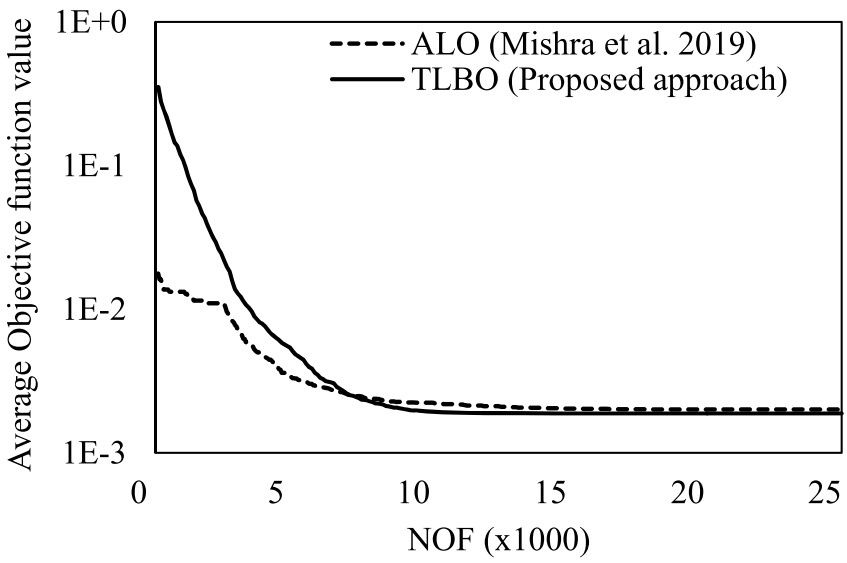

a)

\begin{tabular}{|ll|}
\hline Actual & Hassiotis and Jeong (1995) \\
Hao and Xia (2002) & Maity and Tripathy (2005) \\
ALO (Mishra et al. 2019) & Krishnanunni et al. (2019) \\
TLBO (Proposed Approach) & \\
\hline
\end{tabular}

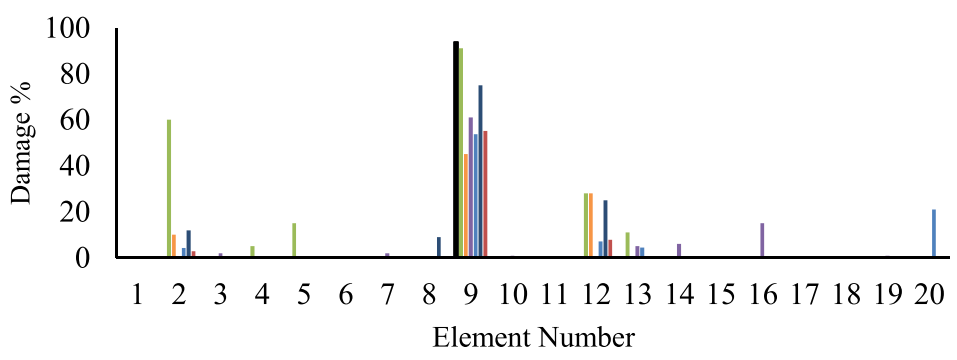


solution point or a student and each column expresses one design variable or a subject. The initial value of $j^{\text {th }}$ design variable for $i^{t h}$ learner is assigned

$X_{i, j}^{1}=X_{j}^{\min }+\operatorname{rand}[0,1] \times\left(X_{j}^{\max }-X_{j}^{\min }\right)$

$X_{j}^{\min }$ and $X_{j}^{\max }$ represents the minimum and maximum allowable values of the $j^{\text {th }}$ variable. The objective function value for each learner represents its performance.

\section{Teaching phase}

The teacher improves the mean performance of a class. The solution with the most desired objective function value in the entire class or solution set is selected as the teacher. Let $M^{g}$ is the vector containing the mean of the design variables of learners and $X_{\text {teacher }}^{g}$ is the teacher at any iteration $g$.
Now a new set of improved learners $X_{\text {new (i) }}^{g}$ is obtained as

$X_{\text {new }(i)}^{g}=X_{i}^{g}+\operatorname{rand}[0,1] \times\left(X_{\text {teacher }}^{g}-M^{g} \times T_{F}\right)$

Where, $T_{F}$ is the teaching factor which randomly takes two equally probable discrete values 1 or 2 as

$T_{F}=\operatorname{round}(1+\operatorname{rand}[0,1])$

If $X_{\text {new }(i)}^{g}$ is a superior solution point with better objective function value $(O F V)$ than $X_{i}^{g}$ in iteration $g$, then it replaces the inferior solution point $X_{i}^{g}$ in the solution set.

\section{Learning phase}

Learners or the students accumulate knowledge by two procedures, one from the insights given by the teacher and another from the interaction with other students. A student improves if the other student has more knowledge, i.e., a better objective function value. In the learning phase, learner
Fig. 6 Damage estimated with $\mathrm{GA}, \mathrm{ACO}_{R}$, UPSO and TLBO in plane frame for various damage scenarios (without noise)
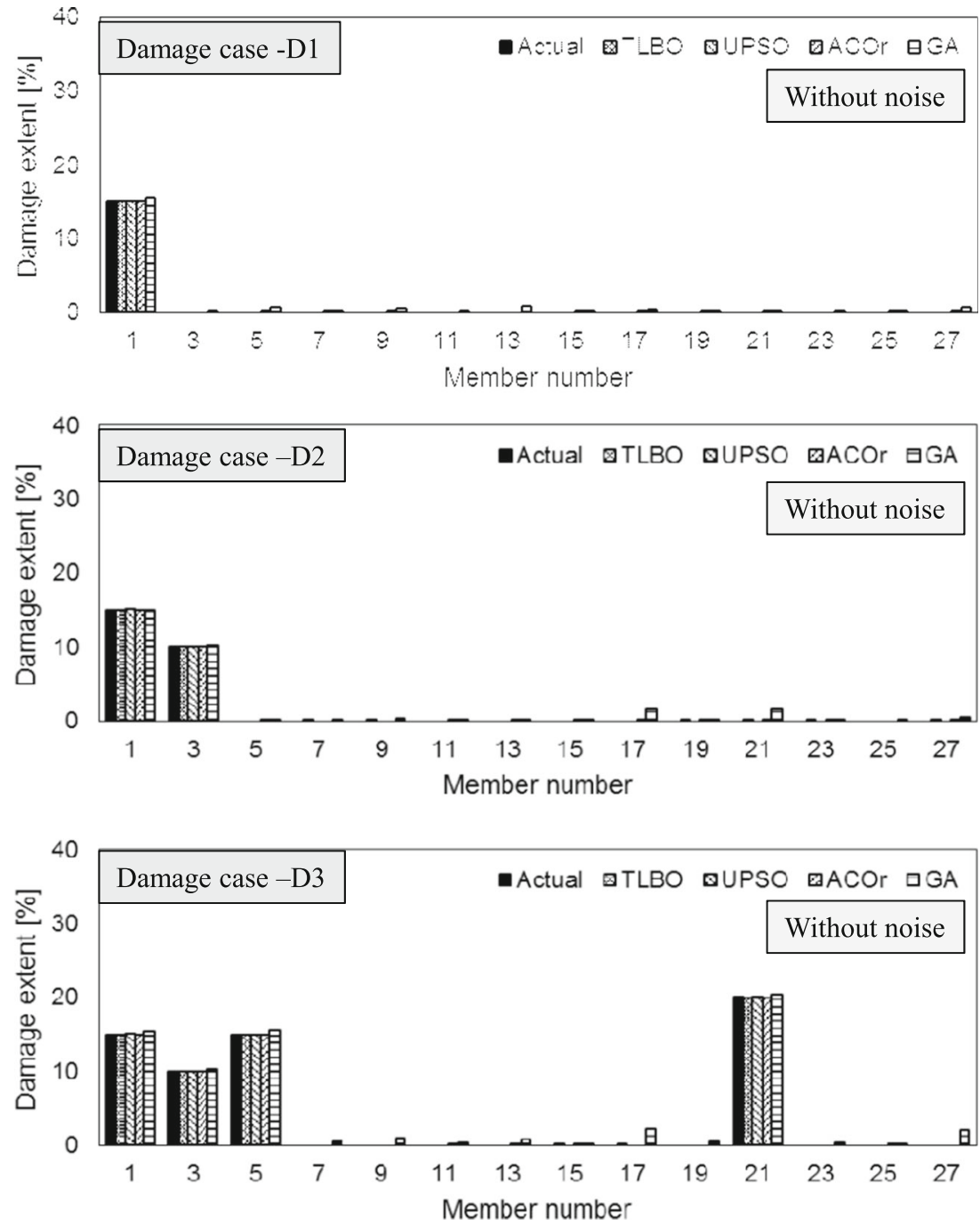
$X_{i}^{g}$ improves from another randomly selected learner $X_{r}^{g}$ $(i \neq r)$ as

$$
X_{\text {new }(i)}^{g}=X_{i}^{g}+\operatorname{rand}[0,1] \times\left(X_{i}^{g}-X_{r}^{g}\right) \text { if OFV }\left(X_{i}^{g}\right)>O F V\left(X_{r}^{g}\right)
$$

otherwise

$X_{n e w(i)}^{g}=X_{i}^{g}+\operatorname{rand}[0,1] \times\left(X_{r}^{g}-X_{i}^{g}\right)$ if OFV $\left(X_{r}^{g}\right)>O F V\left(X_{i}^{g}\right)$

Again, if $X_{\text {new (i) }}^{g}$ is a superior solution point with better objective function value (OFV) than $X_{i}^{g}$ in iteration $g$, then it replaces the inferior solution point $X_{i}^{g}$ in the solution set.

\section{Termination phase}

If the maximum iterations are performed or desired accuracy in objective function value is achieved or allotted run time is over, the algorithm is terminated. Else, it again goes to teaching phase. The steps of TLBO approach for damage detection in frame structures are summarised in the flowchart of Fig. 1.

\section{Damage detection in frames: numerical studies}

Various metaheuristic algorithms have been able to detect damages with satisfactory accuracy for small scale structures, which were equally reported in different literatures. However, for large scale structures involving a large number of elements, these algorithms have not been investigated extensively. There is a possibility that with an increase in the number of elements, i.e., in the number of problem dimensions, some algorithms might not be effective. In this study, TLBO is applied on both small-scale and large-scale frame structures with single and multiple damage sites. It is already reported to be more efficient for damage detection in large scale trusses than most of the well-known
Fig. 7 Damage estimated with $\mathrm{GA}, \mathrm{ACO}_{R}$, UPSO and TLBO in plane frame for various damage scenarios (with noise)
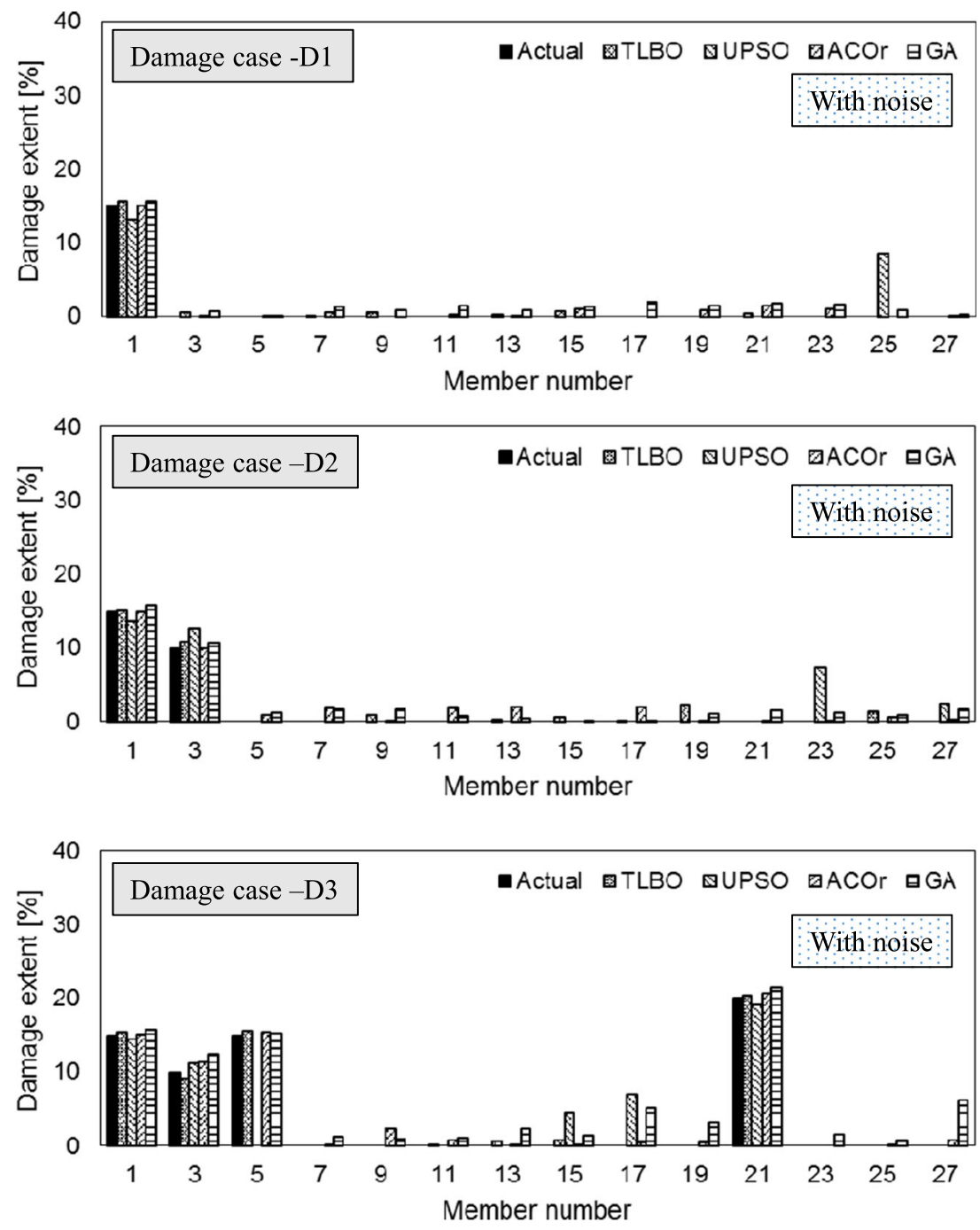
metaheuristic algorithms [4]. Here, multi-storey plane and space frame structures are investigated. To compare performance, GA, UPSO which is an improved version of PSO [80] and real-coded ant colony optimization $\left(\mathrm{ACO}_{R}\right)$, which is an improved version of ACO for continuous domain [81] are chosen.

For GA, in-built MATLAB GA tool [82] is used. For numerical studies, a small-scale 28 -element plane frame (Fig. 2) and a large scale 60-element space frame (Fig. 3), both from Majumdar et al. [83], are considered. Here the terms 'small scale' and 'large scale' refer to the number of elements in the structure rather than indicating the actual dimension. Scaling down or up the actual dimension will not affect the numerical analysis and predicted damage because the performance of an optimization algorithm is dependent on the variable-space dimension, i.e., number of elements, and not the measurable length, width or height of the structure.

The other properties regarding the geometric and material aspects as well as the damaged states are listed in Table 1. Here, 15\%@ $E_{1}$ indicates 15\% stiffness reduction at element number 1 . The other damage scenarios are also expressed in a similar manner.

TLBO does not have any algorithm-specific parameter. For UPSO, unification factor $\mu=0.5$, constriction coefficient $\chi=0.729$, cognition parameter $c_{1}=2.05$ and social parameter $c_{2}=2.05$ is considered. For $\mathrm{ACO}_{R}$, speed of convergence $\xi=1$ and search locality $q=0.5$ is considered. For GA, default mutation and crossover probabilities in MATLAB are used. For all numerical cases, the first six natural frequencies and corresponding mode shapes are taken as the dynamic response from undamaged and damaged structures.

In real practice, this modal information can be obtained by measuring the ambient vibration of the structure, which are usually generated due to unusual live loads, strong wind loads or rare earthquake loads. Measuring ambient vibration to obtain modal response is a popular practice when the structure is large and not suitable for conventional methods of forced excitation risking local damage. Although any of the displacements, velocity and acceleration time history response can be used theoretically, in practical purpose acceleration responses are used, which are usually obtained by accelerometers placed at each beam-column junction. Depending on the availability, accelerometers can be placed more densely near the suspected damage components, and sparsely at the components far away from suspected damaged area, and then model reduction technique can be used to match the simulated FEM degree of freedom responses with measured degree of freedom responses [84]. One of the many approaches to modal identification using only ambient response is

Table 2 Damages predicted for plane frame using GA, $\mathrm{ACO}_{R}$, UPSO and TLBO with standard deviation values $(\sigma)$ (shown inside parenthesis below corresponding range) and $95 \%$ confidence intervals (CI)

\begin{tabular}{|c|c|c|c|c|c|c|c|c|}
\hline \multirow{2}{*}{$\begin{array}{l}\text { Actual } \\
\text { damage }\end{array}$} & \multicolumn{2}{|l|}{ GA } & \multicolumn{2}{|l|}{$\mathrm{ACO}_{R}$} & \multicolumn{2}{|l|}{ UPSO } & \multicolumn{2}{|l|}{ TLBO } \\
\hline & predicted & $95 \% \mathrm{CI}$ & predicted & $95 \% \mathrm{CI}$ & predicted & $95 \% \mathrm{CI}$ & predicted & $95 \% \mathrm{CI}$ \\
\hline \multicolumn{9}{|c|}{ Damage case D1 (for 3-bay, 4-storey plane frame) } \\
\hline $1 @ 15 \%$ & $14.21-16.87$ & $15.31-16.38$ & $14.94-17.61$ & $14.81-15.83$ & $0.00-15.03$ & $10.56-16.44$ & $14.97-15.03$ & $14.98-15.00$ \\
\hline- & $(0.87)$ & - & $(0.82)$ & - & $(4.74)$ & - & $(0.02)$ & - \\
\hline \multicolumn{9}{|c|}{ Damage case D2 (for 3-bay, 4-storey plane frame) } \\
\hline $1 @ 15 \%$ & $13.80-16.95$ & $15.33-16.44$ & $14.96-17.34$ & $14.80-15.72$ & $13.76-16.45$ & $14.60-15.40$ & $14.94-15.03$ & $14.97-15.01$ \\
\hline- & $(0.90)$ & - & $(0.75)$ & - & $(0.65)$ & - & $(0.03)$ & - \\
\hline $3 @ 10 \%$ & $6.53-12.32$ & $9.35-11.08$ & $9.86-12.92$ & $9.66-10.83$ & $0-10.09$ & $5.51-10.53$ & $9.94-10.03$ & $9.93-9.95$ \\
\hline- & $(1.39)$ & - & $(0.94)$ & - & $(4.05)$ & - & $(0.02)$ & - \\
\hline \multicolumn{9}{|c|}{ Damage case D3 (for 3-bay, 4-storey plane frame) } \\
\hline $1 @ 15 \%$ & $8.36-29.33$ & $13.31-20.52$ & $12.07-19.19$ & $14.02-16.13$ & $14.25-21.40$ & $14.47-17.19$ & $14.94-15.00$ & $14.96-14.98$ \\
\hline- & $(5.82)$ & - & $(1.71)$ & - & $(2.20)$ & - & $(0.02)$ & - \\
\hline $3 @ 10 \%$ & $8.29-22.26$ & $9.88-14.95$ & $8.93-10.12$ & $9.68-10.11$ & $0-10.09$ & $2.23-8.46$ & $9.96-10.00$ & $9.97-9.99$ \\
\hline- & $(4.09)$ & - & $(0.34)$ & - & $(5.36)$ & - & $(0.02)$ & - \\
\hline $5 @ 15 \%$ & $9.46-31.12$ & $13.30-20.77$ & $13.80-20.24$ & $14.22-16.41$ & $0-15.07$ & $10.00-15.72$ & $14.91-14.98$ & $14.94-14.96$ \\
\hline- & $(6.02)$ & - & $(1.77)$ & - & $(4.61)$ & - & $(0.02)$ & - \\
\hline $21 @ 20 \%$ & $16.96-28.18$ & $20.28-24.05$ & 16.51-19.95 & 18.06-19.91 & $0-21.37$ & $13.65-21.55$ & $19.86-19.97$ & $19.90-19.94$ \\
\hline- & $(3.04)$ & - & $(1.50)$ & - & $(6.37)$ & - & $(0.03)$ & - \\
\hline
\end{tabular}


utilizing joint approximate diagonalization. A detailed study of the methodology and the implementation is provided by McNeil and Zimmerman [85]. There are also other available time-frequency techniques suitable for different types of structures and environmental conditions, which are discussed by Ramirez et al. [86] in detail. Here, in this study, we assume that the modal identification is already carried out from the acceleration response of the structure and modal information is available to use for the optimizationbased damage detection part. To simulate this data, we use the mathematical modal analysis on the FEM model of the structure directly.

For all numerically modelled damage cases, a noise-free condition (N00) and a noisy condition with upto $1 \%$ noise in a)

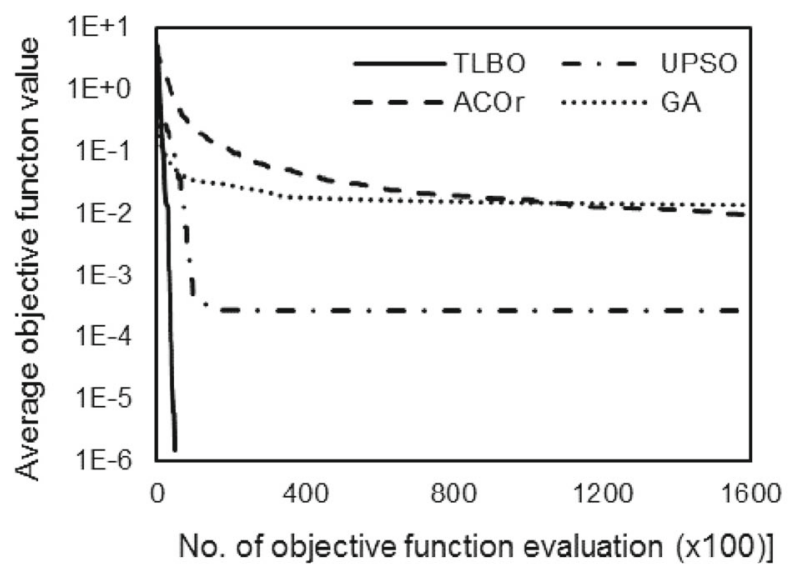

c)

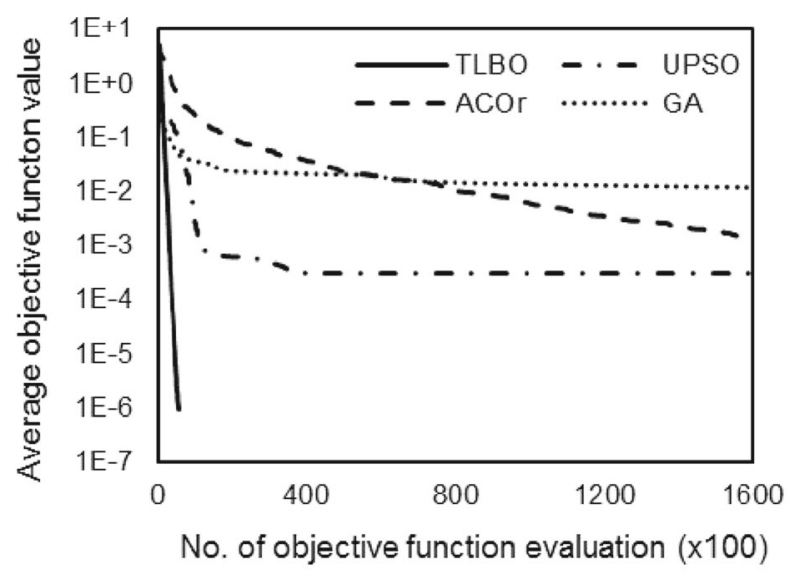

e)

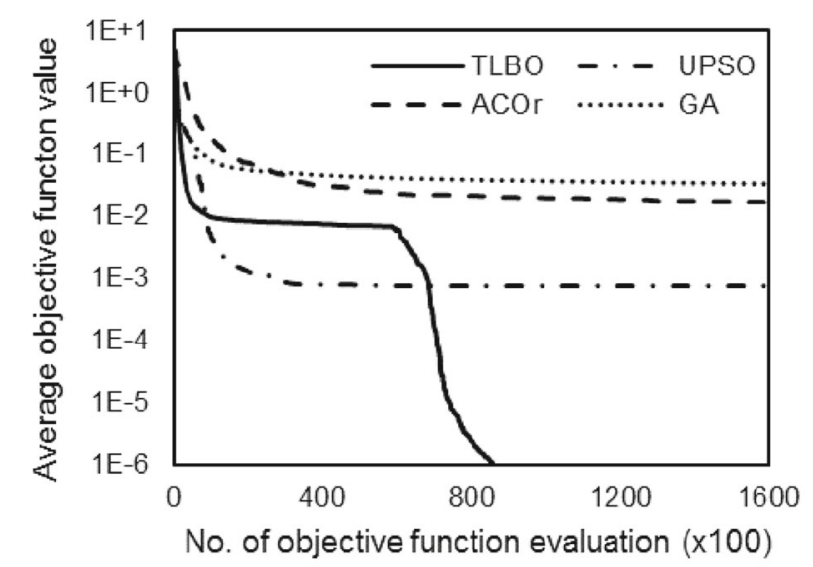

b)

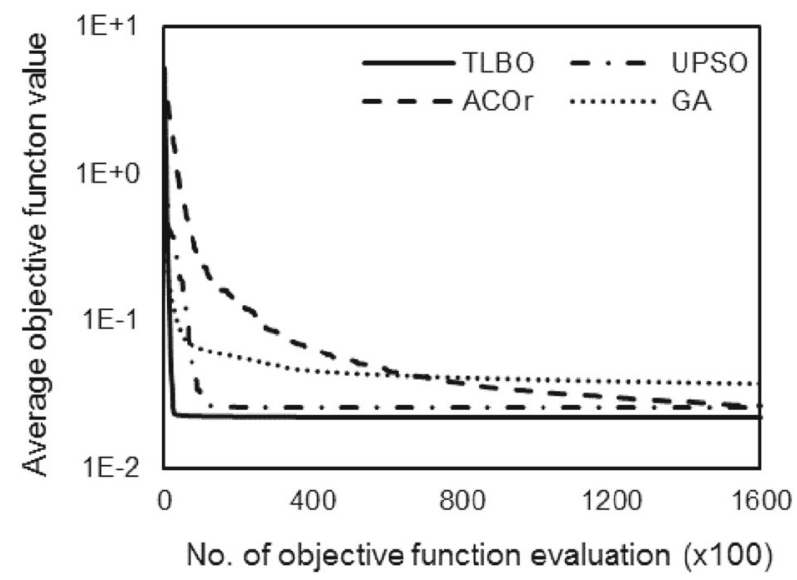

d)

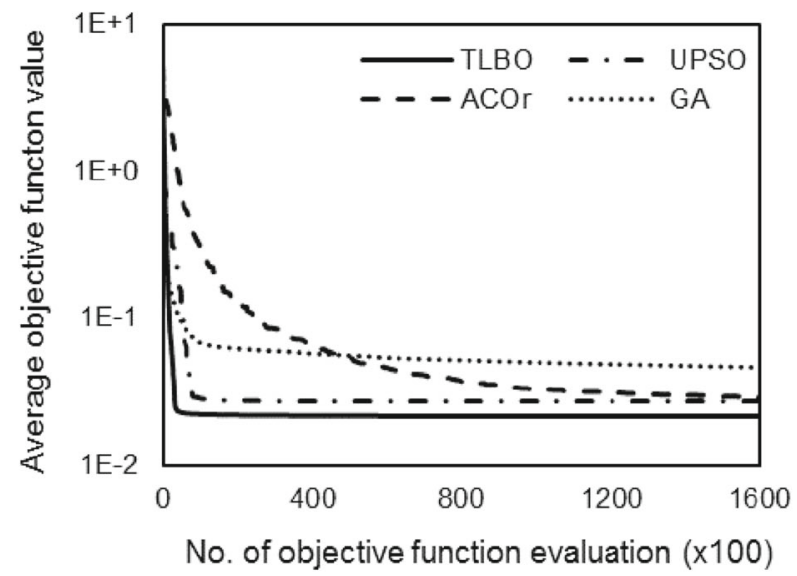

f)

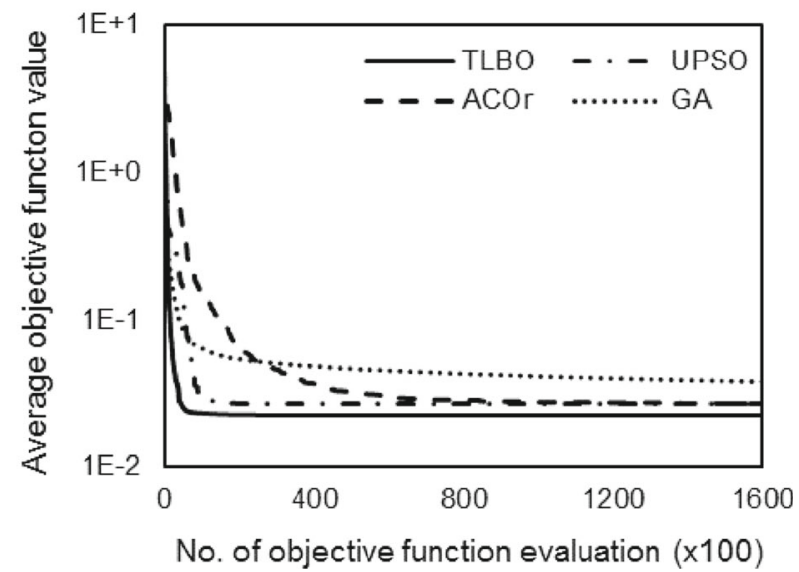

Fig. 8 OFV vs function evaluation for plane frame a) D1; b) D1 (with noise); c) D2; d) D2 (with noise); e) D3; f) D3 (with noise) 
natural frequency and upto $10 \%$ noise in mode shapes (N10) are considered. For example, damage case D2-N10 signifies damage case number 2 with $10 \%$ noise.

$f_{\text {noise }}=f_{\text {numerical }}\left(1+\frac{R \times N}{100}\right)$.

$\phi_{\text {noise }}=\phi_{\text {numerical }}\left(1+\frac{R \times N}{100}\right)$.

where $N$ signifies the noise level and $\mathrm{R}$ is the random number generated between -1 to 1 .

Results are obtained from 10 numerical experiments for each case. For all cases, the algorithms are allowed to run until an objective function value lower than $1 \times 10^{-5}$ is achieved or the number of objective function evaluation exceeds 160000 for the plane frame and 120000 for the space frame, whichever happens earlier. For each damage case, best estimates and average convergence of 10 simulations (numerical runs) are plotted for each algorithm. Confidence intervals of estimated damages are also calculated as a measure of algorithmic consistency.

\section{Validation with experimental results}

The proposed approach is validated against experimental data on an aluminium cantilever beam taken from the research paper of Yang et al. [22]. The dimensions of the beam and the induced damages by making a saw cut are illustrated in Fig. 4 with actual damage in element 9 being $93.75 \%$ induced by the saw cut reducing moment of inertia to $1 / 16$ of previous value. The response of the beam due to impact load was captured using accelerometers and subsequently spectral analysis was used to obtained first six frequencies by Yang et al. [22].

The FEM code was written in MATLAB and the structure was discretized into 20 beam elements and modal updating was carried out with the experimental data. The goal is to

Table 3 Summary of numerical study for damage detection in plane frame

\begin{tabular}{|c|c|c|c|c|c|c|c|}
\hline \multirow{2}{*}{$\begin{array}{l}\text { Damage } \\
\text { case }\end{array}$} & \multirow[t]{2}{*}{ Algorithm } & \multicolumn{2}{|l|}{ NOF } & \multicolumn{2}{|l|}{ OFV } & \multirow{2}{*}{$\begin{array}{l}\text { Success } \\
\text { rate }\end{array}$} & \multirow[b]{2}{*}{ Time(sec) } \\
\hline & & Mean & S.D. & Mean & S.D. & & \\
\hline \multirow[t]{4}{*}{ D1-N00 } & GA & 160000 & - & 0.0138 & 0.0130 & $10 / 10$ & 421 \\
\hline & $\mathrm{ACO}_{R}$ & 138012 & 25228.7 & 0.0093 & 0.0187 & $8 / 10$ & 350 \\
\hline & UPSO & 24960 & 47753.1 & $2.76 \times 10^{-4}$ & $8.61 \times 10^{-4}$ & $10 / 10$ & 59.1 \\
\hline & TLBO & 2920 & 987 & $5.27 \times 10^{-6}$ & $3.60 \times 10^{-6}$ & $10 / 10$ & 6.2 \\
\hline \multirow[t]{4}{*}{ D1-N10 } & GA & 160000 & - & 0.0378 & 0.0196 & $7 / 10$ & 415 \\
\hline & $\mathrm{ACO}_{R}$ & 160000 & - & 0.0268 & 0.0758 & $6 / 10$ & 437 \\
\hline & UPSO & 160000 & - & 0.0261 & 0.0039 & $7 / 10$ & 417 \\
\hline & TLBO & 160000 & - & 0.0222 & 0.00201 & $10 / 10$ & 422 \\
\hline \multirow[t]{4}{*}{ D2 } & GA & 160000 & - & 0.0114 & 0.0146 & $6 / 10$ & 413 \\
\hline & $\mathrm{ACO}_{R}$ & 111144 & 39763 & 0.0015 & 0.0041 & $7 / 10$ & 273 \\
\hline & UPSO & 48640 & 59830 & $3.15 \times 10^{-4}$ & $6.71 \times 10^{-4}$ & $8 / 10$ & 116 \\
\hline & TLBO & 4208 & 902.3 & $7.37 \times 10^{-6}$ & $2.59 \times 10^{-6}$ & $10 / 10$ & 8.4 \\
\hline \multirow[t]{4}{*}{ D2-N10 } & GA & 160000 & - & 0.0461 & 0.0288 & $3 / 10$ & 412 \\
\hline & $\mathrm{ACO}_{R}$ & 160000 & - & 0.0288 & 0.0156 & $4 / 10$ & 432 \\
\hline & UPSO & 160000 & - & 0.0275 & 0.00429 & $5 / 10$ & 410 \\
\hline & TLBO & 160000 & - & 0.0218 & 0.00173 & $10 / 10$ & 421 \\
\hline \multirow[t]{4}{*}{ D3 } & GA & 160000 & - & 0.0344 & 0.0350 & $4 / 10$ & 417 \\
\hline & $\mathrm{ACO}_{R}$ & 76316 & 58494 & 0.0168 & 0.0274 & $4 / 10$ & 187 \\
\hline & UPSO & 94160 & 70393 & $7.45 \times 10^{-4}$ & $1.04 \times 10^{-3}$ & $6 / 10$ & 233 \\
\hline & TLBO & 20296 & 23062.21 & $9.44 \times 10^{-6}$ & $6.51 \times 10^{-7}$ & $10 / 10$ & 42 \\
\hline \multirow[t]{4}{*}{ D3-N10 } & GA & 160000 & - & 0.0379 & 0.0172 & $2 / 10$ & 411 \\
\hline & $\mathrm{ACO}_{R}$ & 160000 & - & 0.0265 & 0.0174 & $1 / 10$ & 427 \\
\hline & UPSO & 160000 & - & 0.00271 & 0.00445 & $4 / 10$ & 410 \\
\hline & TLBO & 160000 & - & 0.00023 & 0.00164 & $10 / 10$ & 417 \\
\hline
\end{tabular}


tune FEM model that is as similar to the original as possible and accurately reproduces the experimental frequencies before damage. Hence, the stiffness of each element was varied in the range of $\pm \delta k$ to arrive to stiffness distribution that closely replicated the experimentally obtained values. For the objective function, only first six natural frequencies of undamaged and damaged beam were chosen as they were available from the experimental data by Yang et al. [22], hence the objective function didn't consider the mode shape. However, for the numerical studies with plane and space frame, both natural frequencies and mode shapes of first six modes were used. Furthermore, in experimental validation example natural frequency measurements are adequate to detect the damage since the structure is asymmetrical, and no mode shape measurements are taken. The following natural frequency based objective function was used in the experimental validation only:

$O F V=\sqrt{\frac{1}{n} \sum_{i=1}^{n}\left(\frac{f_{i}^{d}}{f_{i}^{a}}-1\right)^{2}}$
The performance of the proposed TLBO approach was compared with previous research studies in which Lagrange multiplier method [87], GA [34], and ALO [4] was used in identifying damage extent. Since, the frequencies were obtained from experimental data, hence experimental noises were inherently present, so damage at some extra locations were also obtained (i.e., elements 2, 8 and 12). As can be seen from Fig. 5b, the proposed TLBO approach is able to detect damages and shows a slightly better convergence with the previously used ALO approach [4] (Fig. 5a). TLBO also doesn't show damage in element 2, 5, 12, and 13, which were identified as $60 \%, 15 \%, 28 \%$ and $11 \%$ damaged respectively by Lagrange multiplier method employed by Hassiotis and Jeong [87]. The performance of the proposed approach is better with the GA used by Maity and Tripathy [34], as their approach detected significant false damage in element 16 (15\%). Additionally, GA employed by Hao and Xia [88], showed additional damages in elements 2 and 12, apart from damage identified correctly in element 9 of $45 \%$ as compared to actual value of $93.75 \%$. More
Fig. 9 Damage estimated with $\mathrm{GA}, \mathrm{ACO}_{R}$, UPSO and TLBO in space frame for various damage scenarios (without noise)
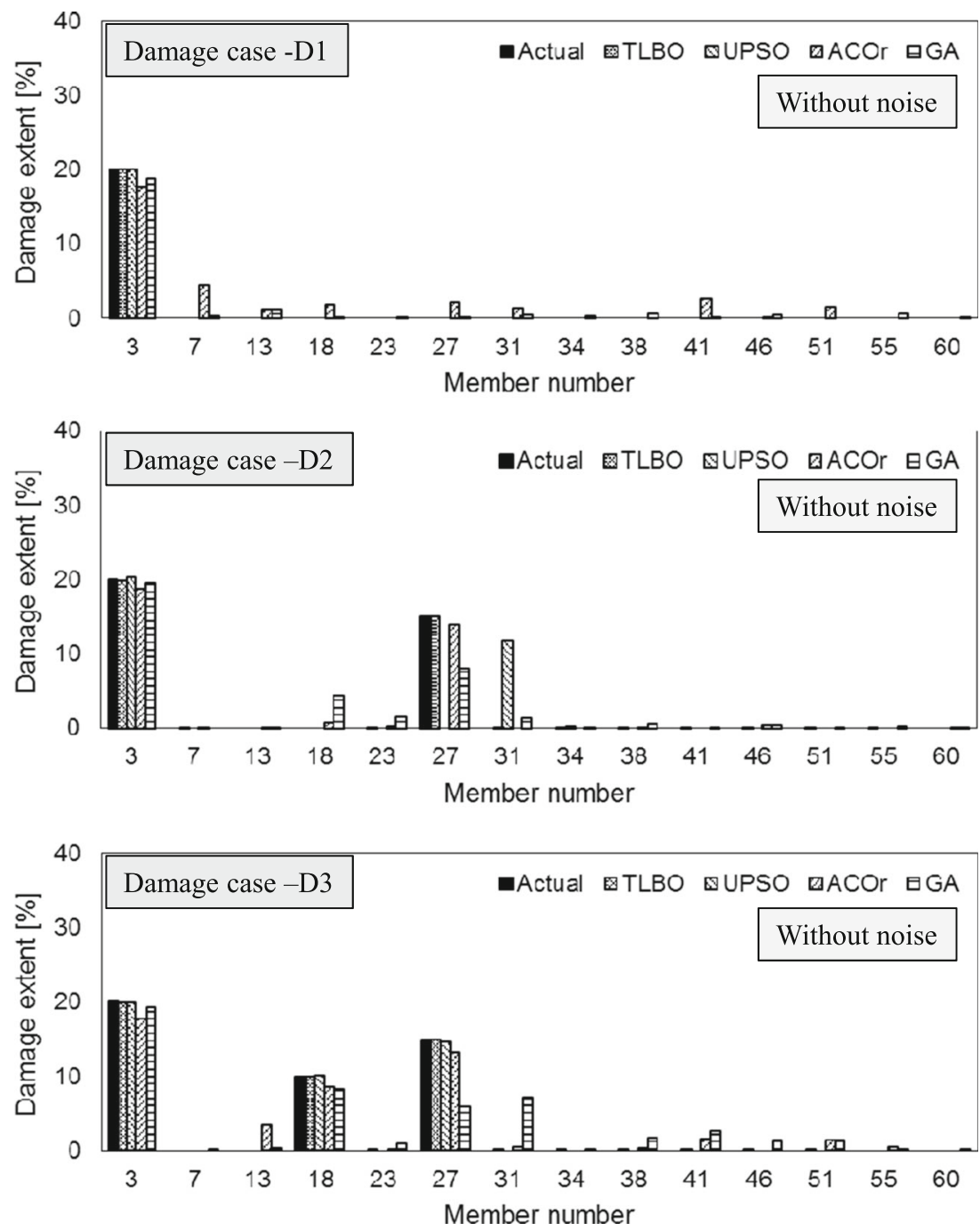
recent study by Krishnanunni et al. [89] identified damages more closely (75\%) with actual value; but it also identified false damages in elements 2 and 12 of more than $10 \%$ and $20 \%$ respectively. When compared with ALO, the results show more consistency in detecting damage, as the uncertainty in damage detection is significantly reduced. The damage in element 9 ranged from 55.22-55.23 with standard deviation of 0.0045 , as compared to ALO which was from 41.29-58.00 having standard deviation of 7.4434. Thus, the proposed method is validated against a benchmark problem containing experimental vibration data.

\section{Results for plane frame}

For the cases with and without measurement noise, the best estimated damage extents with GA, $\mathrm{ACO}_{R}$, UPSO, and TLBO are plotted in Figs. 6 and 7. All the three damage cases are identified correctly with the all the algorithms, however the success rate of proposed TLBO is higher. For noisy cases, estimated damage extents are not accurate but fairly close to the actual values and some small extra damages are also estimated in addition to the actual ones (Fig. 7).

The estimated damage extents for the plane frame from TLBO, UPSO, $\mathrm{ACO}_{R}$ and GA for all damage case are summarised and quantified in Table 2. Based on the results reported, it can be seen that TLBO has the smallest 95\% confidence interval compared to the other three, i.e. damage detected falls well within the neighbourhood of the actual damage extent. This indicates the superior consistency of TLBO, which demonstrates the suitability of this algorithm on real structures. The $95 \%$ confidence interval (CI) is precise having least variation in uncertainty, which is measured by the standard deviation $(\sigma)$ of the damage identified.

Although the damage detection capabilities of algorithms in terms of estimated damage extents may seem similar from Figs. 6 and 7, from the convergence plot (Fig. 8) it can be observed that TLBO achieves the target objective function value of $1 \times 10^{-5}$ with a lesser number of function
Fig. 10 Damage estimated with $\mathrm{GA}, \mathrm{ACO}_{R}$, UPSO and TLBO in space frame for various damage scenarios (with noise)
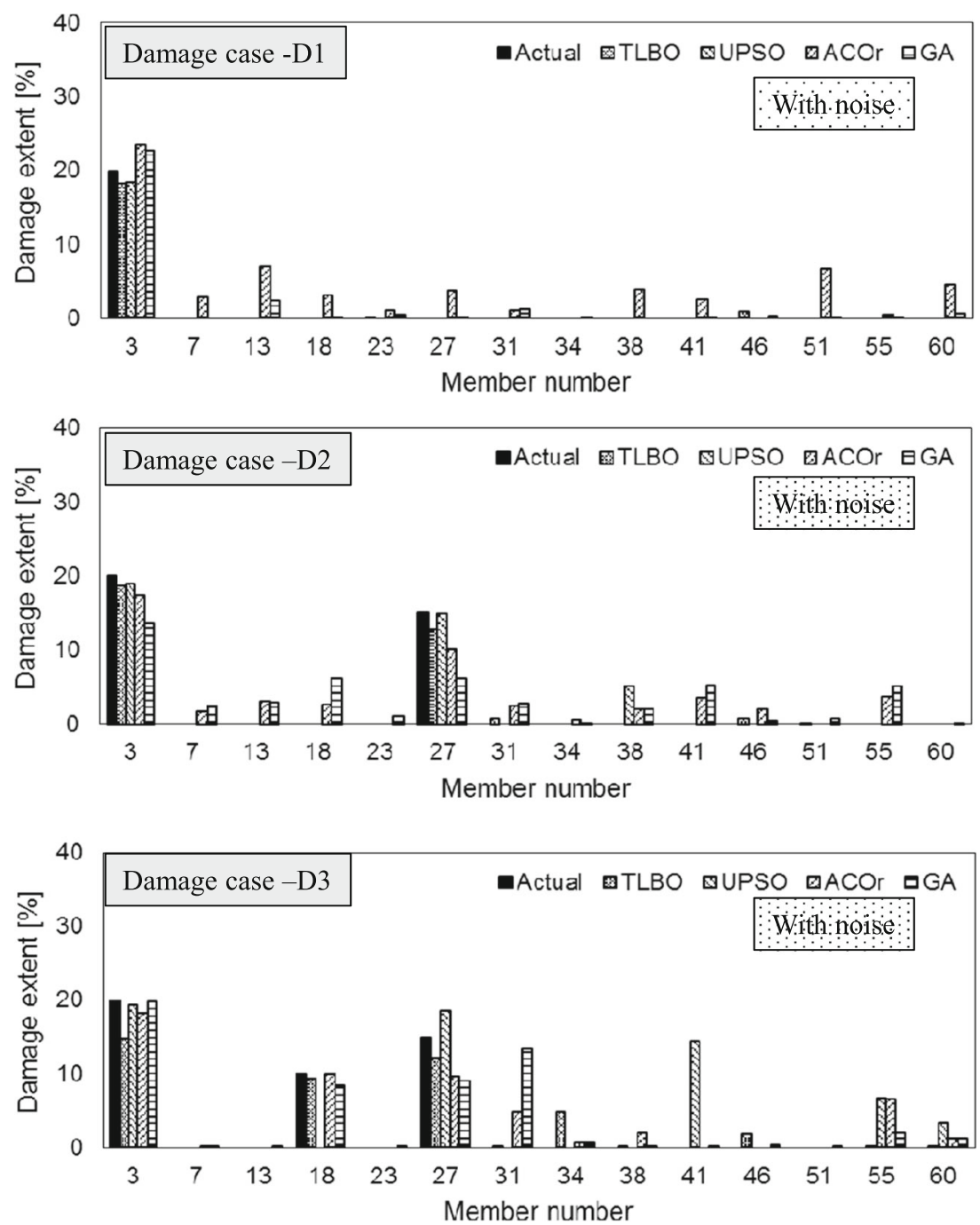
evaluation than GA, ACO and UPSO for all three noisefree damage cases (Table 3). Also, the convergence plot (Fig. 8) shows TLBO is better than GA, $\mathrm{ACO}_{R}$, and UPSO in terms of achieving a lower objective function value for the noisy cases which indicates more accuracy. The success rate in identifying and quantifying damage is $100 \%$ for all 10 simulation runs in the case of TLBO, while similar consistency is not obtained by $\mathrm{GA}, \mathrm{ACO}_{R}$ and UPSO.

a)

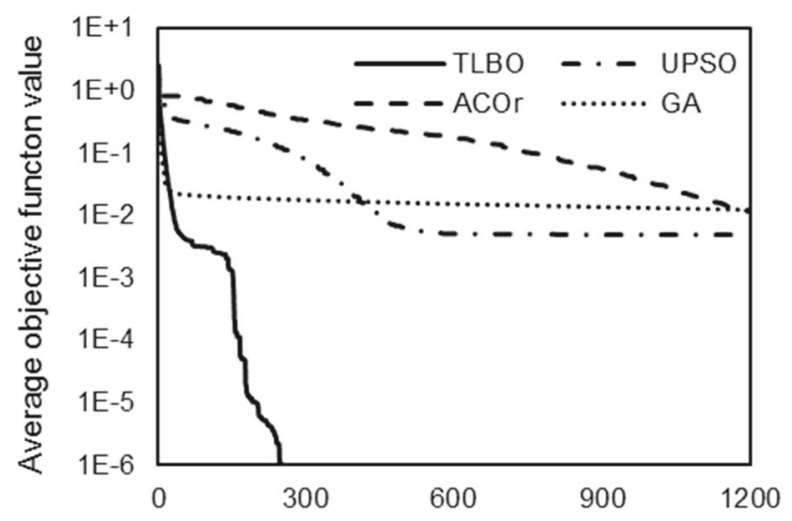

No. of objective function evaluation $(x 100)$

c)

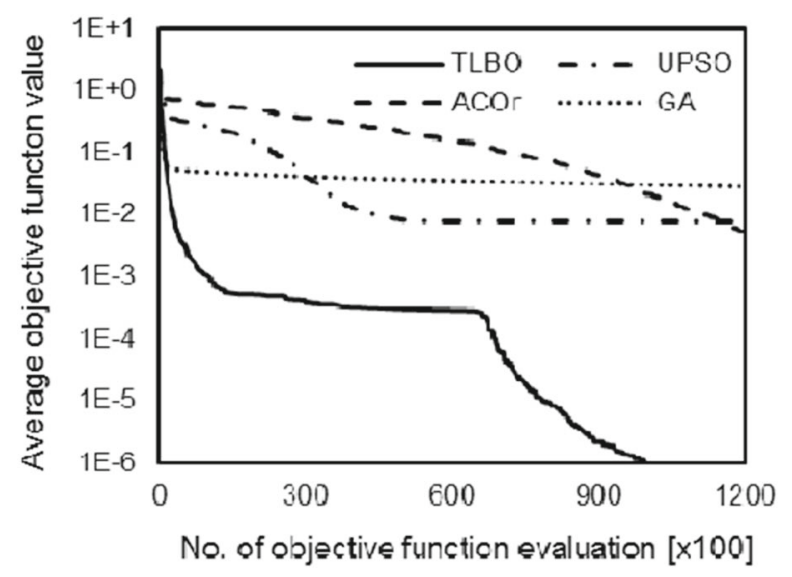

e)

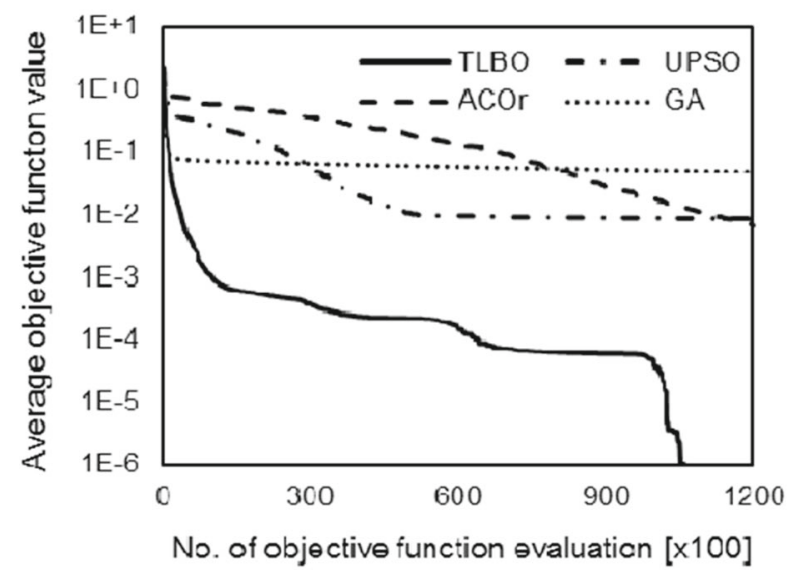

\section{Results for space frame}

In the case of space frame also, the best estimated damage extents with all four algorithms are plotted for both noise-free and noisy cases. Figures 9 and 10 shows the results for three damage scenarios without measurement noise. It is observed that TLBO produced best estimates consistently for all 10 simulations. However, for multiple damage-point cases, it gave good estimates in very few

b)

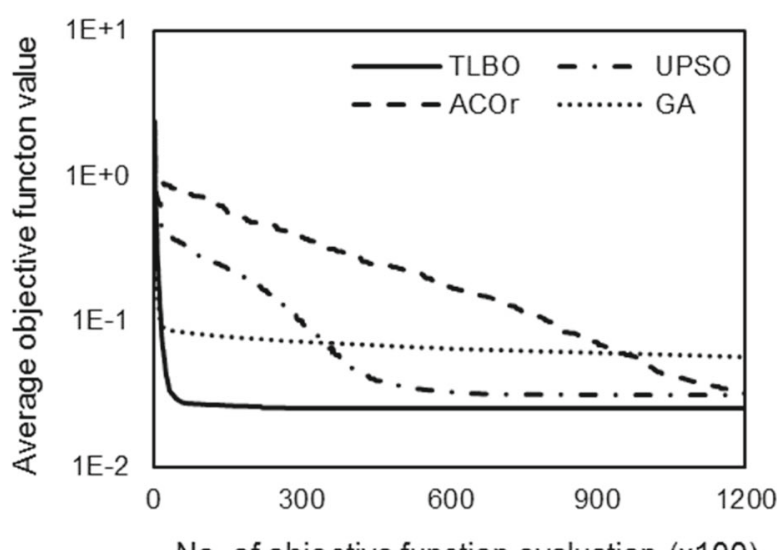

d)

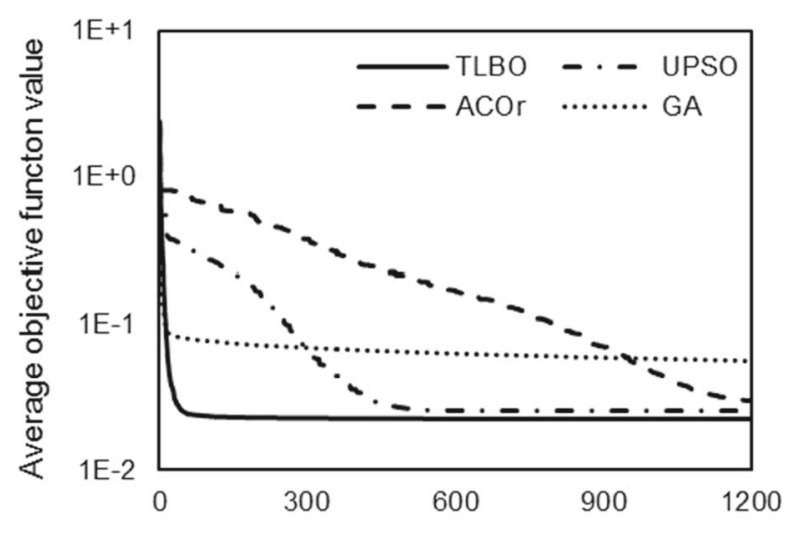

No. of objective function evaluation $(x 100)$

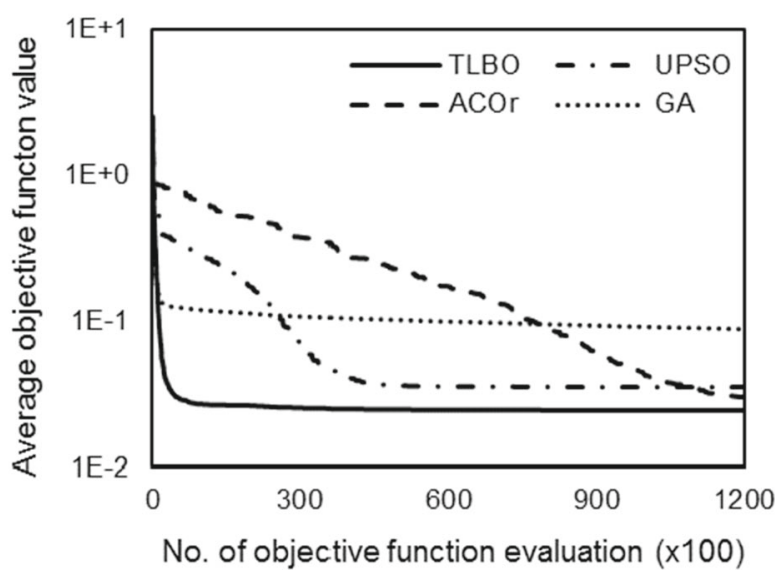

Fig. 11 OFV vs function evaluation for space frame a) D1; b) D1 (with noise); c) D2; d) D2 (with noise); e) D3; f) D3 (with noise) 
simulations. After TLBO, $\mathrm{ACO}_{R}$ showed most consistency even though the best estimate of $\mathrm{ACO}_{R}$ is inferior to the best estimate of UPSO. This phenomenon is also reflected in the convergence plot of noise-free multiple damage cases (Fig. 11), where averaged final converged value of $\mathrm{ACO}_{R}$ is lower than UPSO. GA converged at a much higher value compared to the other three which indicates least accuracy. Only TLBO can achieve the target objective function value of $1 \times 10^{-5}$ for noise-free cases with a lesser number of function evaluations. For noisy cases, TLBO produced least amount of additional false damages and produced better estimates (Fig. 10), and it converged to slightly lower value compared to UPSO, $\mathrm{ACO}_{R}$ and GA.

The estimated damage extents for the space frame from TLBO, UPSO and $\mathrm{ACO}_{R}$ for all damage case are summarised in Table 4. From Table 4, we can see that for all noise-free cases, TLBO provides better estimates with smaller CI. GA, $\mathrm{ACO}_{R}$ and UPSO fails to detect damage for three-element cases (i.e., damage case D3). The most probable reason for this might be the divergent tendency of $\mathrm{GA}, \mathrm{ACO}_{R}$ and UPSO which occurs with a large number of design variables. Success rate of TLBO again in noisefree cases again is $100 \%$ as reported in Table 5 as compared to almost $0 \%$ for GA, $50-60 \%$ for $\mathrm{ACO}_{R}$ and $20-40 \%$ for UPSO. The success rate is defined if all the damage extents in a damage scenario are identified with a bound of $\pm 3 \%$.

From the results, a significant improvement of is found while using TLBO compared to GA, UPSO and
$\mathrm{ACO}_{R}$ both in terms of uncertainty reduction in damage prediction $(\sigma)$, success rates and number of objective function evaluations as quantified in Tables 2-5. Since most of the computation time comes from the finite element analysis part for large-scale models, they are equivalent when comparing the relative performance. For the noise free cases, TLBO obtained the desired solution with significantly smaller number of objective function evaluations. Since objective function evaluation includes carrying out the computationally costly FEA part, this resulted in a strikingly low detection time for TLBO. This is observed for both 28 -element plane frame and 60-element space frame. Also, from the convergence plot and $95 \%$ CI interval values, we observe that TLBO can attain the desired closeness to the true optimum or the exact damage extent consistently. For space frame cases, although best damage estimated by UPSO is better than damage estimated by $\mathrm{ACO}_{R}$, a lower standard deviation of $\mathrm{ACO}_{R}$ indicates better consistency. However, TLBO has significantly lower standard deviation compared to these two and GA for all the cases. For both plane and space frame, TLBO has very small $\mathrm{CI}$ and also the standard deviation less than 0.3. On the contrary, $\mathrm{ACO}_{R}$, UPSO and GA has much broader CI range and larger standard deviation often higher than 1 and reaching upto 20 for space frame.

TLBO has 100\% success rate in both plane and space frames with noise-free cases for detecting correct damaged states, which is much higher compared to other three. For

Table 4 Damages predicted for space frame using GA, $\mathrm{ACO}_{R}$, UPSO and TLBO with standard deviation values $(\sigma)$ (shown inside parenthesis below corresponding range) and $95 \%$ confidence intervals (CI)

\begin{tabular}{|c|c|c|c|c|c|c|c|c|}
\hline \multirow{2}{*}{$\begin{array}{l}\text { Actual } \\
\text { damage }\end{array}$} & \multicolumn{2}{|l|}{ GA } & \multicolumn{2}{|c|}{$\mathrm{ACO}_{R}$} & \multicolumn{2}{|l|}{ UPSO } & \multicolumn{2}{|l|}{ TLBO } \\
\hline & predicted & $95 \% \mathrm{CI}$ & predicted & $95 \% \mathrm{CI}$ & predicted & $95 \% \mathrm{CI}$ & predicted & $95 \% \mathrm{CI}$ \\
\hline \multicolumn{9}{|c|}{ Damage case D1 (for 5-storey space frame) } \\
\hline $3 @ 20 \%$ & $0.00-18.82$ & $0.53-8.44$ & $0.00-18.87$ & $1.52-13.45$ & $0.00-20.01$ & $3.47-16.53$ & 19.84-19.99 & $19.86-19.93$ \\
\hline- & $(6.39)$ & - & $(9.63)$ & - & $(10.53)$ & - & $(0.05)$ & - \\
\hline \multicolumn{9}{|c|}{ Damage case D2 (for 5-storey space frame) } \\
\hline $3 @ 20 \%$ & $0.00-19.59$ & 4.74-14.15 & $0.00-26.53$ & $12.93-21.14$ & $0.00-20.36$ & $0.00-12.30$ & 19.67-19.92 & 19.86-19.97 \\
\hline- & $(7.59)$ & - & $(6.61)$ & - & $(10.13)$ & - & $(0.09)$ & - \\
\hline $27 @ 15 \%$ & $0.00-58.40$ & $0.63-21.13$ & $0.03-17.63$ & $8.58-14.51$ & $0-15.00$ & $0.00-2.82$ & $14.62-15.05$ & $14.75-14.92$ \\
\hline- & $(17.57)$ & - & $(4.78)$ & - & $(4.52)$ & - & $(0.14)$ & - \\
\hline \multicolumn{9}{|c|}{ Damage case D3 (for 5-storey space frame) } \\
\hline $3 @ 20 \%$ & $0.00-69.82$ & $1.27-27.38$ & $0.08-20.94$ & $9.60-19.19$ & $0.00-19.91$ & $1.52-13.81$ & $19.65-19.96$ & $19.73-19.86$ \\
\hline- & $(21.06)$ & - & $(7.73)$ & - & $(9.92)$ & - & $(0.11)$ & - \\
\hline $18 @ 10 \%$ & $0.01-34.82$ & $2.98-17.53$ & $0.83-11.65$ & $5.29-10.02$ & $0.00-11.61$ & $0.00-5.98$ & $9.87-10.16$ & $9.92-10.05$ \\
\hline- & (11.73) & - & $(3.81)$ & - & $(4.86)$ & - & $(0.11)$ & - \\
\hline $27 @ 15 \%$ & $0.00-42.59$ & $2.49-18.88$ & $0.00-17.32$ & $6.86-14.67$ & $0.00-19.17$ & $1.64-11.61$ & $14.36-15.03$ & $14.68-14.91$ \\
\hline- & (13.22) & - & $(6.30)$ & - & $(8.04)$ & - & $(0.19)$ & - \\
\hline
\end{tabular}


Table 5 Summary of numerical study for damage detection in space frame

\begin{tabular}{|c|c|c|c|c|c|c|c|}
\hline \multirow{2}{*}{$\begin{array}{l}\text { Damage } \\
\text { case }\end{array}$} & \multirow[t]{2}{*}{ Algorithm } & \multicolumn{2}{|l|}{$\mathrm{NOF}$} & \multicolumn{2}{|l|}{ OFV } & \multirow{2}{*}{$\begin{array}{l}\text { Success } \\
\text { rate }\end{array}$} & \multirow[b]{2}{*}{ Time(sec) } \\
\hline & & Mean & S.D. & Mean & S.D. & & \\
\hline \multirow[t]{4}{*}{ D1 } & GA & 120000 & - & 0.0125 & 0.00901 & $1 / 10$ & 4715 \\
\hline & $\mathrm{ACO}_{R}$ & 120000 & - & 0.00117 & 0.00601 & $6 / 10$ & 4392 \\
\hline & UPSO & 85560 & 37820 & 0.00492 & 0.00654 & $4 / 10$ & 3162 \\
\hline & TLBO & 12592 & 7319 & $7.58 \times 10^{-6}$ & $2.19 \times 10^{-6}$ & $10 / 10$ & 497 \\
\hline \multirow[t]{4}{*}{ D1-N10 } & GA & 120000 & - & 0.0563 & 0.0676 & $1 / 10$ & 4283 \\
\hline & $\mathrm{ACO}_{R}$ & 120000 & - & 0.00322 & 0.00845 & $5 / 10$ & 4247 \\
\hline & UPSO & 120000 & - & 0.0311 & 0.0155 & $2 / 10$ & 4336 \\
\hline & TLBO & 120000 & - & 0.00254 & 0.00399 & $9 / 10$ & 4544 \\
\hline \multirow[t]{4}{*}{ D2 } & GA & 120000 & - & 0.0280 & 0.0561 & $0 / 10$ & 4669 \\
\hline & $\mathrm{ACO}_{R}$ & 120000 & - & 0.00507 & 0.00835 & $5 / 10$ & 4336 \\
\hline & UPSO & 120000 & - & 0.00787 & 0.00463 & $2 / 10$ & 4512 \\
\hline & TLBO & 23936 & 27784 & $9.25 \times 10^{-6}$ & $4.23 \times 10^{-7}$ & $10 / 10$ & 934 \\
\hline \multirow[t]{4}{*}{ D2-N10 } & GA & 120000 & - & 0.0562 & 0.0670 & $0 / 10$ & 4396 \\
\hline & $\mathrm{ACO}_{R}$ & 120000 & - & 0.0302 & 0.00464 & $3 / 10$ & 4166 \\
\hline & UPSO & 120000 & - & 0.0256 & 0.00341 & $2 / 10$ & 4366 \\
\hline & TLBO & 120000 & - & 0.0228 & 0.00284 & $5 / 10$ & 4530 \\
\hline \multirow[t]{4}{*}{ D3 } & GA & 120000 & - & 0.04589 & 0.00708 & $0 / 10$ & 4630 \\
\hline & $\mathrm{ACO}_{R}$ & 120000 & - & 0.00665 & 0.00536 & $5 / 10$ & 4414 \\
\hline & UPSO & 117480 & 11763 & 0.00843 & 0.00743 & $2 / 10$ & 4360 \\
\hline & TLBO & 32368 & 29063 & $9.10 \times 10^{-6}$ & $7.25 \times 10^{-7}$ & $10 / 10$ & 1242 \\
\hline \multirow[t]{4}{*}{ D3-N10 } & GA & 120000 & - & 0.0870 & 0.0888 & $0 / 10$ & 4286 \\
\hline & $\mathrm{ACO}_{R}$ & 120000 & - & 0.0301 & 0.00481 & $3 / 10$ & 4186 \\
\hline & UPSO & 120000 & - & 0.0346 & 0.00694 & $1 / 10$ & 4325 \\
\hline & TLBO & 120000 & - & 0.0244 & 0.00447 & $4 / 10$ & 4508 \\
\hline
\end{tabular}

the noisy cases also, TLBO produced much better results in terms of achieving the closest values to the true damage scenario and consistency compared to the other three algorithms. Although the algorithm is run till it exhausted the maximum number of allowed iterations, from the convergence curve for noisy cases it can be observed that the lowest OFV among all four algorithms is achieved by TLBO at much earlier stage of the simulation. This performance difference is more prominent for space frame with large number of elements, where even other efficient variants of well-established algorithms are not much accurate or consistent. Hence, in the practical situation of detecting damage in a frame structure or a multi-storey building, where the response is expected to be noisy, TLBO can be extremely effective in regards to the higher accuracy of the detection, significantly low computational time even without considering the additional benefit of bypassing parameter-calibration, and better consistency of predicted damage. In addition, it is observed that the detection accuracy drops with increase in the number of damage locations for all algorithms. So, this detection methodology with TLBO is expected to be more effective in case of early damage incorporation in frames and can be effective structural monitoring solution for multi-storey buildings.

As far as computation time is concerned, there it is reduced to $1 / 14$ from $1 / 5$ for plane frame and 1/6 from $1 / 3$ for space frame for cases without noise. Furthermore, similar reduction is obtained in number of function evaluations (NOFs), which is $1 / 9$ from $1 / 4$ for plane frame and $1 / 7$ from $1 / 3$ for space frame for cases without noise. The comparison values are compared with best of GA, $\mathrm{ACO}_{R}$ and UPSO and the TLBO approach. 


\section{Conclusions}

In this study, the feasibility and benefits of using relatively new soft computing algorithm TLBO are rigorously investigated to detect single and multiple location damage in frame structures and a benchmark problem of cantilever beam. Both plane frame and space frame are considered. The performance of TLBO is compared with UPSO, $\mathrm{ACO}_{R}$, and GA (efficient on small problem dimensions) for frame structures and other literature approaches for cantilever beam. In addition to noise-free cases, cases with measurement noises are also taken into account to simulate real-life scenarios. A benchmark cantilever beam with actual experimental data is also considered. The performance of TLBO is compared with UPSO, $\mathrm{ACO}_{R}$, and GA (efficient on small problem dimensions). It must be noted that for noisy cases some false damage locations (although negligible damage extent) might also be detected; owing to error in vibration data due to inclusion of noise. The inverse problem of damage identification is highly nonconvex and false damages are often identified even without inclusion of noise due to the large number of local optima. For without noise cases, some small damage $(\leq 5 \%)$ may be predicted for some of the undamaged members which can be ignored for practical purpose. However, false damage prediction of higher magnitudes for one or more undamaged members for noise-free cases should be considered as the failure of the algorithm to predict the damage scenario. For noisy cases, inclusion of noise changes the dynamic response and can shift the optima to a damage scenario where some undamaged members should have significant damage extents to display the similar dynamic response. Some possible ways to mitigate the effect of noise is using high-precision measurement instruments, taking average of several measured responses or applying noise-reduction techniques of post-processing on the measured dynamic response.

Despite the efficiency of the proposed TLBO technique for structural damage detection in the numerical simulations, it must be pointed out that the some of the aspects such as damages in initiation phase in both noise-free and noisy environment are not covered and must be expanded for future studies. For example, most realistic damage scenarios, implementation to large scale structures, and implementation of TLBO for optimized sensor location. In our study, only the first six natural frequencies and the mode shapes associated with them are considered for the objective function. Other dynamic responses like FRF, mode shape curvature and flexibility matrix could be further studied to improve the estimation accuracy for noisy cases. Also, two stage methods can be utilized to roughly indicate the possibly damaged members and hence reduce the optimization problem dimensionality which might improve the damage prediction accuracy.

\section{Declarations}

Conflict of Interests The authors declare that they have no conflict of interest.

\section{References}

1. Ferraioli M, Miccoli L, Abruzzese D (2018) Dynamic characterisation of a historic bell-tower using a sensitivity-based technique for model tuning. J Civ Struct Heal Monit 8(2):253269

2. Mayank M, Barman SK, Maity D, Maiti DK (2020a) Performance studies of 10 metaheuristic techniques in determination of damages for large-scale spatial trusses from changes in vibration responses. J Comput Civ Eng 34(2):04019052

3. Nobari AS, Ferri Aliabadi MH (2018) Vibration-Based techniques for damage detection and localization in engineering structures, vol 10. World Scientific, Singapore

4. Mishra M, Barman SK, Maity D, Maiti DK (2019a) Ant lion optimisation algorithm for structural damage detection using vibration data. J Civ Struct Heal Monit 9(1):117-136

5. Mishra M (2020) Machine learning techniques for structural health monitoring of heritage buildings: A state-of-the-art review and case studies. J Cult Herit

6. Nanda B, Maity D, Maiti DK (2012) Vibration based structural damage detection technique using particle swarm optimization with incremental swarm size. Int J Aeronaut Space Sci 13(3):323331

7. Das S, Saha P (2021) Performance of swarm intelligence based chaotic meta-heuristic algorithms in civil structural health monitoring. Measurement 169:108533

8. Kaveh A, Hosseini SM, Akbari H (2020) Efficiency of plasma generation optimization for structural damage identification of skeletal structures based on a hybrid cost function. Iran J Sci Technol Trans Civ Eng pp 1-22

9. Dorigo M, Gambardella LM (1997) Ant colonies for the travelling salesman problem. Biosystems 43(2):73-81

10. Kennedy J, Eberhart R (1995) Particle swarm optimization in Neural networks. In: Proceedings IEEE international conference on 1995, pp 1942-1948

11. Na C, Kim S-P, Kwak H-G (2011) Structural damage evaluation using genetic algorithm. J Sound Vib 330(12):27722783

12. Bai M, Wang L, Guo Y (2014) Layout optimization of sensorbased reconstruction of explosion overpressure field based on the genetic algorithm. Smart Sci 2(4):185-190

13. Iqbal D, Ahmad T, Pervez I, Malick IH, Sarwar A, Tariq M (2020) Performance of pso based variants in tracking optimal power in a solar pv based generation system under partial shading condition. Smart Sci 8(1):1-13

14. Mishra M, Gunturi VR, Miranda TFDS (2019b) Slope stability analysis using recent metaheuristic techniques: a comprehensive survey. SN Appl Sci 1(12):1-17

15. Jiang C, Xue $X$ (2021) A uniform compact genetic algorithm for matching bibliographic ontologies. Appl Intell pp 1-16

16. Goodwin M, Granmo O-C, Radianti J (2015) Escape planning in realistic fire scenarios with ant colony optimisation. Appl Intell 42(1):24-35 
17. Mishra M, Basson MS, Ramana GV, Vassallo R (2020b) Ant colony optimization for slope stability analysis applied to an embankment failure in eastern India. Int J Geo-Eng 11(1):1-16

18. Ning Y, Peng Z, Dai Y, Bi D, Wang J (2019) Enhanced particle swarm optimization with multi-swarm and multi-velocity for optimizing high-dimensional problems. Appl Intell 49(2):335351

19. Pholdee N, Bureerat S (2016a) Structural health monitoring through meta-heuristics-comparative performance study. Adv Comput Des 1(4):315-327

20. Shahrouzi M, Sabzi A-H (2018) Damage detection of truss structures by hybrid immune system and teaching-learning-based optimization. Asian J Civ Eng 19(7):811-825

21. Barman SK, Mishra M, Maiti DK, Maity D (2021) Vibrationbased damage detection of structures employing bayesian data fusion coupled with TLBO optimization algorithm. Struct Multidiscip Optim pp 1-24

22. Yang JCS, Tsai T, Pevlin V, Chen J, Tsai WH (1985) Structural damage detection by the system identification technique. Shock Vib Inf Cent Shock Vib Bull 55:57-65

23. Doyle JF (1994) Crack detection in frame structures. ASME Appl Mech Div Publ-AMD 186:17-17

24. Ceravolo R, De Stefano A, Sabia D (1995) Hierarchical use of neural techniques in structural damage recognition. Smart Mater Struct 4(4):270

25. Kosmatka JB, Ricles JM (1999) Damage detection in structures by modal vibration characterization. J Struct Eng 125(12):1384-1392

26. Pandey AK, Biswas M, Samman MM (1991) Damage detection from changes in curvature mode shapes. J Sound Vib 145(2):321332

27. Wang Q, Deng X (1999) Damage detection with spatial wavelets. Int J Solids Struct 36(23):3443-3468

28. Sampaio RPC, Maia NMM, Silva JMM (1999) Damage detection using the frequency-response-function curvature method. Int $\mathbf{J}$ Solids Struct 226(5): 1029-1042

29. Zou Y, Tong LPSG, Steven GP (2000) Vibration-based modeldependent damage (delamination) identification and health monitoring for composite structures-a review. J Sound Vib 230(2):357-378

30. Lopez-Pacheco M, Morales-Valdez J, Yu W (2020) Frequency domain cnn and dissipated energy approach for damage detection in building structures. Soft Comput pp 1-20

31. Tripathy RR, Maity D (2004) Damage assessment of structures from changes in curvature damage factor using artificial neural network

32. Maity D, Saha A (2004) Damage assessment in structure from changes in static parameter using neural networks. Sadhana 29(3):315-327

33. Krawczuk M (2002) Application of spectral beam finite element with a crack and iterative search technique for damage detection. Finite Elem Anal Des 38(6):537-548

34. Maity D, Tripathy RR (2005) Damage assessment of structures from changes in natural frequencies using genetic algorithm. Struct Eng Mech 19(1):21-42

35. Moaveni B, He X, Conte JP, De Callafon RA (2008) Damage identification of a composite beam using finite element model updating. J Comput Aided Civ Infrastruct Eng 23(5):339-359

36. Fang S-E, Perera R (2009) Power mode shapes for early damage detection in linear structures. J Sound Vib 324(1-2):40-56

37. Chen B, Zang C (2009) Artificial immune pattern recognition for structure damage classification. Comput Struct 87(21-22):13941407

38. Sahoo B, Maity D (2007) Damage assessment of structures using hybrid neuro-genetic algorithm. Appl Soft Comput 7(1):89-104
39. Meruane V, Heylen W (2011) An hybrid real genetic algorithm to detect structural damage using modal properties. Mech Syst Sig Process 25(5): 1559-1573

40. Vallabhaneni V, Maity D (2011) Application of radial basis neural network on damage assessment of structures. Procedia Eng 14:3104-3110

41. Bandara RP, Chan TH, Thambiratnam DP (2014) Frequency response function based damage identification using principal component analysis and pattern recognition technique. Eng Struct 66:116-128

42. Yu L, Xu P (2011) Structural health monitoring based on continuous ACO method. Microelectron Reliab 51(2):270-278

43. Majumdar A, Maiti DK, Maity D (2012) Damage assessment of truss structures from changes in natural frequencies using ant colony optimization. Appl Math Comput 218(19):9759-9772

44. Braun CE, Chiwiacowsky LD, Gomez AT (2015) Variations of ant colony optimization for the solution of the structural damage identification problem. Procedia Comput Sci 51:875-884

45. Huang Q, Xu YL, Li JC, Su ZQ, Liu HJ (2012) Structural damage detection of controlled building structures using frequency response functions. J Sound Vib 331(15):3476-3492

46. Mohan SC, Maiti DK, Maity D (2013) Structural damage assessment using FRF employing particle swarm optimization. Appl Math Comput 219(20):10387-10400

47. Sandesh S, Shankar K (2010) Application of a hybrid of particle swarm and genetic algorithm for structural damage detection. Inverse Probl Sci Eng Formerly Inverse Probl Eng 18(7):997-1021

48. Pal J, Banerjee S (2015) A combined modal strain energy and particle swarm optimization for health monitoring of structures. J Civ Struct Heal Monit 5(4):353-363

49. Nouri Shirazi MR, Mollamahmoudi H, Seyedpoor SM (2014) Structural damage identification using an adaptive multi-stage optimization method based on a modified particle swarm algorithm. J Optim Theory Appl 160(3):1009-1019

50. Wei Z, Liu J, Lu Z (2018) Structural damage detection using improved particle swarm optimization. Inverse Probl Sci Eng 26(6):792-810

51. Jebieshia TR, Maiti DK, Maity D (2015) Damage assessment of composite structures using particle swarm optimization. Int $\mathrm{J}$ Aerosp Syst Eng 2(2):24-28

52. Jebieshia TR, Maiti DK, Maity D (2017) Damage detection of laminated composite shells using unified particle swarm optimization. In: Proceedings of ICTACEM 2017 international conference on theoretical, applied, computational and experimental mechanics, pp 28-30

53. Shakya A, Mishra M, Maity D, Santarsiero G (2019) Structural health monitoring based on the hybrid ant colony algorithm by using hooke-jeeves pattern search. SN Appl Sci 1(7):799

54. Kaveh A, Zolghadr A (2015) An improved css for damage detection of truss structures using changes in natural frequencies and mode shapes. Adv Eng Softw 80:93-100

55. He R-S, Hwang S-F (2006) Damage detection by an adaptive realparameter simulated annealing genetic algorithm. Comput Struct 84(31-32):2231-2243

56. Ding ZH, Huang M, Lu Z-R (2016) Structural damage detection using artificial bee colony algorithm with hybrid search strategy. Swarm Evol Comput 28:1-13

57. Mohamad Dehcheshmeh M, Ghodrati Amiri G, Zare Hosseinzadeh A, Torbatinejad V (2020) Structural damage detection based on modal data using moth-flame optimisation algorithm. Proc Inst Civ Eng-Struct Build pp 1-15

58. Zhu JJ, Huang M, Lu Z-R (2017) Bird mating optimizer for structural damage detection using a hybrid objective function. Swarm Evol Comput 35:41-52 
59. Boonlong K (2014) Vibration-based damage detection in beams by cooperative coevolutionary genetic algorithm. Adv Mech Eng 6:624949

60. Ding Z, Zhao Y, Lu Z (2019) Simultaneous identification of structural stiffness and mass parameters based on bare-bones gaussian tree seeds algorithm using time-domain data. Appl Soft Comput 83:105602

61. Kim N-I, Kim S, Lee J (2019) Vibration-based damage detection of planar and space trusses using differential evolution algorithm. Appl Acoust 148:308-321

62. Aval SBB, Mohebian P (2020) Combined joint and member damage identification of skeletal structures by an improved biology migration algorithm. J Civ Struct Heal Monit pp 1-19

63. Ghahremani B, Bitaraf M, Rahami H (2020) A fast-convergent approach for damage assessment using cma-es optimization algorithm and modal parameters. J Civ Struct Heal Monit pp 1-15

64. Barman SK, Maiti DK, Maity D (2020) Damage detection of truss employing swarm-based optimization techniques: A comparison. In: Advanced engineering optimization through intelligent techniques. Springer, pp 21-37

65. Rao VR, Savsani VJ, Vakharia DP (2011) Teaching-learningbased optimization: a novel method for constrained mechanical design optimization problems. Comput Aided Des 43(3):303-315

66. Dede T (2014) Application of teaching-learning-basedoptimization algorithm for the discrete optimization of truss structures. KSCE J Civ Eng 18(6):1759-1767

67. Rao VR, Patel V (2013) An improved teaching-learning-based optimization algorithm for solving unconstrained optimization problems. Sci Iran 20(3):710-720

68. Camp CV, Farshchin M (2014) Design of space trusses using modified teaching-learning based optimization. Eng Struct 62:8797

69. Tejani GG, Savsani VJ, Patel VK (2016) Modified sub-population teaching-learning-based optimization for design of truss structures with natural frequency constraints. Mech Based Des Struct Mach 44(4):495-513

70. Khanduzi R, Ebrahimzadeh A, Peyghami MR (2018) A modified teaching-learning-based optimization for optimal control of volterra integral systems. Soft Comput 22(17):5889-5899

71. Hosseini SMH, Rezvani A (2020) Modeling and simulation to optimize direct power control of dfig in variable-speed pumpedstorage power plant using teaching-learning-based optimization technique. Soft Comput

72. Mishra M, Gunturi VR, Maity D (2020c) Teaching-learningbased optimisation algorithm and its application in capturing critical slip surface in slope stability analysis. Soft Comput 24(4):2969-2982

73. Mukherjee P, Punera D, Mishra M (2021) Coupled flexural torsional analysis and buckling optimization of variable stiffness thin-walled composite beams. Mech Adv Mater Struct, pp 1-21

74. Pholdee N, Bureerat S (2016b) Hybrid TLBO and BFGS for structural health monitoring optimisation problems. In: International symposium on mechanical engineering and material science (ismems-16). Atlantis Press
75. Fallahian S, Joghataie A, Kazemi MT (2018) Structural damage detection using time domain responses and teaching-learningbased optimization (tlbo) algorithm. Sci Iran Trans A Civ Eng 25(6):3088-3100

76. Khatir S, Wahab MA, Boutchicha D, Khatir T (2019) Structural health monitoring using modal strain energy damage indicator coupled with teaching-learning-based optimization algorithm and isogoemetric analysis. J Sound Vib 448:230 246

77. Perera R, Ruiz A (2008) A multistage fe updating procedure for damage identification in large-scale structures based on multiobjective evolutionary optimization. Mech Syst Sig Process 22(4):970-991

78. El Ghazi A, Ahiod B (2018) Energy efficient teaching-learningbased optimization for the discrete routing problem in wireless sensor networks. Appl Intell 48(9):2755-2769

79. Das SP, Achary NS, Padhy S (2016) Novel hybrid SVMTLBO forecasting model incorporating dimensionality reduction techniques. Appl Intell 45(4):1148-1165

80. Parsopoulos KE, Vrahatis MN (2005) Unified particle swarm optimization for solving constrained engineering optimization problems. In: International conference on natural computation. Springer, pp 582-591

81. Socha K, Dorigo M (2008) Ant colony optimization for continuous domains. Eur J Oper Res 185(3):1155-1173

82. (2017) MATLAB. version 9.2.0 R2017a. The mathworks inc natick massachusetts

83. Majumdar A, Nanda B, Maiti DK, Maity D (2014) Structural damage detection based on modal parameters using continuous ant colony optimization. Adv Civ Eng pp 2014

84. Qu Z-Q (2004) Model order reduction techniques with applications in finite element analysis: with applications in finite element analysis. Springer Science \& Business Media, New York

85. McNeill SI, Zimmerman DC (2008) A framework for blind modal identification using joint approximate diagonalization. Mech Syst Sig Process 22(7):1526-1548

86. Perez-Ramirez CA, Amezquita-Sanchez JP, Adeli H, ValtierraRodriguez M, Romero-Troncoso RDJ, Dominguez-Gonzalez A, Osornio-Rios RA (2016) Time-frequency techniques for modal parameters identification of civil structures from acquired dynamic signals. J Vibroengineering 18(5):31643185

87. Hassiotis S, Jeong GD (1995) Identification of stiffness reductions using natural frequencies. J Eng Mech 121(10):1106-1113

88. Hao H, Xia Y (2002) Vibration-based damage detection of structures by genetic algorithm. J Comput Civ Eng 16(3):222229

89. Krishnanunni CG, Sethu Raj R, Nandan D, Midhun CK, Sajith AS, Ameen M (2019) Sensitivity-based damage detection algorithm for structures using vibration data. J Civ Struct Heal Monit 9(1):137-151

Publisher's Note Springer Nature remains neutral with regard to jurisdictional claims in published maps and institutional affiliations. 